University of Nebraska - Lincoln

DigitalCommons@University of Nebraska - Lincoln

2012

\title{
A non-premixed combustion model based on flame structure analysis at supercritical pressures
}

Guilhem Lacaze

Sandia National Laboratories, Livermore, CA

Joseph Oefelein

Sandia National Laboratories, Livermore, CA

Follow this and additional works at: https://digitalcommons.unl.edu/usdoepub

Part of the Bioresource and Agricultural Engineering Commons

Lacaze, Guilhem and Oefelein, Joseph, "A non-premixed combustion model based on flame structure analysis at supercritical pressures" (2012). US Department of Energy Publications. 119.

https://digitalcommons.unl.edu/usdoepub/119

This Article is brought to you for free and open access by the U.S. Department of Energy at DigitalCommons@University of Nebraska - Lincoln. It has been accepted for inclusion in US Department of Energy Publications by an authorized administrator of DigitalCommons@University of Nebraska - Lincoln. 


\title{
A non-premixed combustion model based on flame structure analysis at supercritical pressures
}

\author{
Guilhem Lacaze*, Joseph C. Oefelein \\ Sandia National Laboratories, Livermore, CA 94550, USA
}

\section{A R T I C L E I N F O}

\section{Article history:}

Received 4 July 2011

Received in revised form 2 November 2011

Accepted 1 February 2012

Available online 3 March 2012

\section{Keywords:}

High-pressure combustion

Real-fluid effects

Counterflow diffusion flame

Transcritical regime

Supercritical regime

Flame structure

\begin{abstract}
A B S T R A C T
This work presents a study of non-premixed flames at supercritical-pressure conditions. Emphasis is placed on flame stability in liquid rocket engines fueled with liquid oxygen and gaseous hydrogen. The flame structure sensitivity to strain, pressure, temperature and real-fluid effects was investigated in detailed opposed-jet flames calculations. It is shown that the flame is very robust to strain, that the flamelet assumption is valid for the conditions of interest, and that real-fluid phenomena can have a significant impact on flame topology. At high-pressure supercritical conditions, small pressure or temperature variations can induce strong changes of thermodynamic properties across the flame. A substantial finding was also that the presence of water from combustion significantly increases the critical pressure of the mixture, but this does not lead to a saturated state where two-phase flow may be observed. The present study then shows that a single-phase real-fluid approach is relevant for supercritical hydrogen-oxygen combustion. Resultant observations are used to develop a flamelet model framework that combines detailed real-fluid thermodynamics with a tabulated chemistry approach. The governing equation for energy contains a compressible source term that models the flame. Through this approach, the solver is capable of capturing compressibility and strain-rate effects. Good agreements have been obtained with respect to detailed computations. Heat release sensitivity to strain and pressure variations is also recovered. Consequently, this approach can be used to study combustion stability in actual burners. The approach preserves the density gradient in the high-shear region between the liquid-oxygen jet and product rich flame region. The latter is a key requirement to properly simulate dense-fluid jet destabilization and mixing in practical devices.
\end{abstract}

(C) 2012 The Combustion Institute. Published by Elsevier Inc. All rights reserved.

\section{Introduction}

Practical devices such as gas turbines, diesel engines and rockets operate at elevated pressures that approach and/or exceed the thermodynamic critical point of the propellants. Under these conditions, injected liquid jets undergo a transcritical change of state as fluid temperatures rise above the critical temperature of the local mixture. For this situation, diminished inter-molecular forces promote diffusion dominated mixing processes prior to atomization and injected jets vaporize in the presence of exceedingly large thermophysical gradients. Well-mixed diffusion flames evolve as a consequence and intense property gradients approach the behavior of a contact discontinuity. Significant real-gas effects and transport anomalies coexist locally in colder regions of the flow, with ideal gas and transport processes occurring within the flame zone [1]. The focus for the present work is development of a combustion model for use with the Large Eddy Simulation (LES) technique

\footnotetext{
* Corresponding author.

E-mail addresses: gnlacaz@sandia.gov(G. Lacaze), oefelei@sandia.gov(J.C. Oefelein).
}

[2-7]. This method is very promising to study flame stability, combustion - acoustic coupling, and emissions in actual devices (complex geometry), with detailed thermodynamics and transport.

The goal of this work is to facilitate studies of flame stability in rocket engines fueled with liquid propellants (oxygen and hydrogen) at high pressure. In this type of application, propellants are injected separately and flames are located within the mixing regions. For the present study, an average chamber pressure of 70 bar has been selected, which is above the critical pressures of both reactants $\left(P_{\mathrm{O}_{2}}^{c}=50.4\right.$ bar and $P_{\mathrm{H}_{2}}^{c}=12.9$ bar [8]). In addition to a predictive combustion model, sophisticated models to deal with thermodynamics and transport are required and must be an integral part of the model formulation. The ultimate objective of this work is to develop a combustion model able to capture all processes involved.

Previous experimental and numerical studies reveal that the flamelet approach is relevant to simulate the flame-turbulence interaction in rocket engines. Experimental investigations carried out at supercritical pressure (with respect to oxygen), in rocketlike test rigs that use coaxial injectors [9-16], have shown that the flame stabilizes directly at the injector post in the mixing layer 


\section{Nomenclature}

\begin{tabular}{|c|c|}
\hline \multicolumn{2}{|c|}{ Abbreviations } \\
\hline $\mathrm{GH}_{2}$ & gaseous hydrogen \\
\hline Lox & liquid oxygen \\
\hline st & stoichiometric condition \\
\hline $\mathrm{BC}$ & boundary condition \\
\hline DNS & direct numerical simulation \\
\hline LES & large Eddy simulation \\
\hline LIF & laser induced fluorescence \\
\hline \multicolumn{2}{|l|}{ Symbols } \\
\hline$\chi$ & scalar dissipation rate \\
\hline$\delta_{f l m}$ & flame thickness \\
\hline$\dot{\omega}_{i}$ & molar production rate of the species $i$ \\
\hline$\dot{\omega}_{T}$ & chemical heat release \\
\hline$\dot{Q}_{s}$ & chemical heat release per unit flame surface area \\
\hline$\gamma$ & heat capacity ratio \\
\hline$\lambda$ & thermal conductivity \\
\hline$\mu$ & dynamic viscosity \\
\hline$v$ & molecular viscosity \\
\hline$\rho$ & density \\
\hline$\tau_{c}$ & chemical timescale \\
\hline$\tau_{\chi}$ & diffusion timescale \\
\hline$\tau_{\kappa}$ & Kolomogorov timescale \\
\hline$\tau_{\text {acoustic }}$ & acoustic timescale \\
\hline$\tau$ & viscous stress tensor \\
\hline$a$ & strain rate \\
\hline$C_{v}$ & heat capacity at constant volume \\
\hline$C_{p_{i}}$ & heat capacity at constant pressure of the $i^{\text {th }}$ species \\
\hline$D_{a}$ & Damköhler number \\
\hline$D_{i}$ & diffusion coefficient of the $i^{\text {th }}$ species \\
\hline$D_{t h}$ & thermal diffusion coefficient \\
\hline E & total non-chemical energy \\
\hline$e_{S}$ & sensible energy \\
\hline$H$ & distance between the opposed-jet exits \\
\hline$h_{i}$ & sensible enthalpy of the $i$ th species \\
\hline$h_{t}$ & enthalpy of the mixture \\
\hline$h_{f_{i}}^{\circ}$ & heat of formation of the $i$ th species \\
\hline
\end{tabular}

$L e_{i} \quad$ Lewis number of the $i$ th species

$M \quad$ Mach number

$N$ number of species in the mixture

$P \quad$ pressure

$P^{c} \quad$ critical pressure

$P^{r} \quad$ reduced temperature

$R \quad$ ideal gas constant

Re Reynolds number

$T$ temperature

$t$ time

$T^{c} \quad$ critical temperature

$T^{r} \quad$ reduced temperature

$V \quad$ molar volume

$V_{\text {corr }} \quad$ velocity correction from the Hirschfelder and Curtiss approximation [28]

$W_{i} \quad$ molar mass of the $i$ th species

$x, y, z \quad$ spatial coordinates

$X_{i} \quad$ molar fraction of the $i$ th species

$Y_{i} \quad$ mass fraction of the $i$ th species

$Z \quad$ mixture fraction

$Z_{H} \quad$ mixture fraction based on the $H$ element

Zc compressibility factor

I identity matrix

$\mathbf{q}_{i} \quad$ diffusion flux of the $i$ th species

u velocity vector

Sub-and super-scripts

- reference state

ad adiabatic

$F \quad$ conditions at the fuel boundary

$\mathrm{H}_{2}$ conditions at the $\mathrm{H}_{2}$ boundary

inj injection conditions

model output from the combustion model

$O$ conditions at the oxidizer boundary

$\mathrm{O}_{2} \quad$ conditions at the $\mathrm{O}_{2}$ boundary

ref reference quantity

table output from the look-up table between the fuel and the oxidizer streams. This indicates that combustion occurs in a pure non-premixed mode. Singla et al. [16] used Laser Induced Fluorescence (LIF) of the $\mathrm{OH}$ radical to study the flame structure close to the injector post tip. In this region, the flame is very thin and does not exhibit local extinction. Further downstream, the flame forms close to the oxygen stream and its thickness varies depending on the local strain rate.

The inner structure of $\mathrm{Lox}-\mathrm{H}_{2}$ flames has been studied numerically by Ribert et al. [17] and Juniper et al. [18]. Laminar counterflow flames were used to investigate pressure and strain rates effects. It was shown that the flame is very robust to strain over a large range of sub- and super-critical pressures. In addition, Ivancic and Mayer have investigated timescales based on experimental and numerical works [19]. They found that the Kolomogorov timescale has a magnitude of $\tau_{\kappa} \approx 1 \mu \mathrm{s}$. The characteristic timescale of chemistry can be approximate by: $\tau_{c} \approx\left(\rho Y_{i}\right) /\left(W_{i} \dot{\omega}_{i}\right)$, where $i$ is the index of the least reactive species in the flame and $\dot{\omega}_{i}$ its molar production rate. A chemical analysis of $\mathrm{H}_{2}-\mathrm{O}_{2}$ combustion at elevated pressure shows that $\tau_{c} \approx 0.01 \mu$ s. This comparison shows that the Damköhler number $D_{a}=\tau_{\kappa} / \tau_{c} \gg 1$, which implies that the flame is thin and robust and can be viewed locally as a laminar reacting layer insensitive to unsteady effects (i.e. the flamelet approximation is valid).

To date, the flamelet approach was successfully used by Zong et al. [20] for gaseous-methane/liquid-oxygen combustion in the context of LES at rocket conditions. Schmitt et al. [21] employed a presumed PDF approach coupled with a flamelet tabulation to represent a methane-Lox flame at elevated pressure in an experimental rocket engine. LES results were in good agreement with experimental observations. A similar method was used by Matsuyama et al. $[22,23]$ to model the flame in a $\mathrm{Lox}-\mathrm{GH}_{2}$ rocket engine, and good agreements with experimental shadowgraphs were obtained. In the RANS framework, several numerical studies employed Flamelet models for high pressure combustion, with relative success [24,25]. However, in all these investigations, the impact of high-pressure non-linear effects on the flamelet approach is never discussed. In particular, the question of how the look-up table is generated must be clarified for supercritical combustion. Given these limitations, the objectives of the present study are:

- Study the flame structure of hydrogen-oxygen diffusion flames at the conditions typically observed in rocket engines, to determine the relevant modeling parameters.

- Investigate the impact of high-pressure phenomena on the modeling approach.

- Develop a flamelet model that accounts for these phenomena and test its performance.

To achieve these objectives, we present the theoretical and numerical framework in Section 2 followed by analysis of the flame 
structure in Section 3. In Section 4, findings from the previous sections are used to formulate the combustion model. In the final section, a systematic assessment of the model is then performed.

\section{Theoretical basis and numerical approach}

The theoretical and numerical framework of the present study has been developed by Oefelein [26,27]. This framework has been optimized to meet the algorithm requirements imposed by the LES formalism and was defined to provide an unified treatment of high Reynolds-number, high-pressure, real-gas/liquid reacting flows over a wide Mach operating range.

\subsection{Governing equations}

The formulation solves the fully coupled conservation equations of mass, momentum, total energy and species as follows:

- Mass:

$$
\frac{\partial \rho}{\partial t}+\nabla \cdot(\rho \mathbf{u})=0
$$

where, $\rho$ is the density and $\mathbf{u}$ the three-dimensional velocity vector.

- Momentum:

$$
\frac{\partial}{\partial t}(\rho \mathbf{u})+\nabla \cdot\left[\rho \mathbf{u} \otimes \mathbf{u}+\frac{P}{M^{2}} \mathbf{I}\right]=\nabla \cdot \tau
$$

where

$$
\tau=\frac{\mu}{\operatorname{Re}}\left[-\frac{2}{3}(\nabla \cdot \mathbf{u}) \mathbf{I}+\left(\nabla \mathbf{u}+\nabla \mathbf{u}^{T}\right)\right]
$$

represents the viscous stress tensor. $P, M, \mu$ and Re are the pressure, Mach number, dynamic viscosity and Reynolds number respectively.

- Species:

$$
\frac{\partial}{\partial t}\left(\rho Y_{i}\right)+\nabla \cdot\left(\rho Y_{i} \mathbf{u}\right)=\nabla \cdot \mathbf{q}_{i}+\dot{\omega}_{i} \quad i=1, \ldots, N-1,
$$

where $Y_{i}, \mathbf{q}_{i}$ and $\dot{\omega}_{i}$ represent the mass-fraction, mass diffusion fluxes and rate of production of the $i$ th species, respectively. $\mathbf{q}_{i}$ contains the velocity correction $V^{c}$ (to ensure global mass conservation) resulting from the Hirschfelder and Curtiss approximation [28]:

$$
\mathbf{q}_{i}=-\rho\left(D_{i} \frac{W_{i}}{W} \nabla X_{i}-Y_{i} V_{\text {corr }}\right)
$$

where $X_{i}, D_{i}$ and $W_{i}$ are the molar fraction, the molar diffusivity and the molar mass of the $i$ th species and $W$ is the molar mass of the mixture.

- Total energy:

$$
\frac{\partial}{\partial t}(\rho E)+\nabla \cdot[(\rho E+P) \mathbf{u}]=\nabla \cdot\left[\mathbf{q}_{E}+M^{2}(\tau \cdot \mathbf{u})\right]+\dot{Q}_{E},
$$

where,

$$
\begin{aligned}
& E=e_{s}+\frac{M^{2}}{2} \mathbf{u} \cdot \mathbf{u} \\
& e_{s}=\sum_{i=1}^{N} h_{i} Y_{i}-\frac{P}{\rho} \\
& h_{i}=\int_{p^{\circ}}^{p} \int_{T^{\circ}}^{T} C_{p_{i}}(T, P) d T d p \\
& \dot{Q}_{E}=-\sum_{i=1}^{N} \dot{\omega}_{i} h_{f_{i}}^{\circ}
\end{aligned}
$$

represents the total energy, sensible energy, enthalpy of the $i$ th species, and heat release rate due to chemistry respectively. Term $\mathbf{q}_{E}$ is the energy diffusion flux expressed as:

$$
\mathbf{q}_{E}=-\lambda \nabla T+\sum_{i=1}^{N} \mathbf{q}_{i} h_{i}
$$

where $\lambda$ is the thermal conductivity of the mixture and $T$ the temperature.

These equations are coupled using a cubic equation of state [1] and appropriate treatments of thermodynamic and transport properties to capture correctly supercritical effects occurring at high pressures.

\subsection{Equation of state and thermodynamic properties}

The equation of state employed in the present study is the Peng-Robinson $(P R)$ cubic equation [29,1]:

$P=\frac{R T}{V-b}-\frac{a}{V^{2}+2 b V-b^{2}}$,

where $R$ is the ideal-gas constant and $V$ the molar volume. Terms $a$ and $b$ are coefficients that account for attraction and repulsion effects among molecules. They are calculated using a set of nonlinear mixing-rules that can be found in Reid et al. [1, Chapter 4]. This equation has been chosen because it is more suitable for conditions when the temperature is greater than the critical temperature, which is the case in the flame. A summary of the cubic equations of state and recommended constants is also given by Reid et al. [1, Chapter 3].

A property evaluation scheme developed by Oefelein [30] is used to determine the thermodynamic properties. Having established an analytical representation for real mixture PVT behavior, the thermodynamic properties are obtained in two steps. First, respective component properties are combined at a fixed temperature using the corresponding states methodology to obtain the mixture state at a given reference pressure. A pressure correction is then applied using departure functions of the form given by Reid et al. [1, Chapter 5]. These functions have the form:

$h_{i}(T, \rho)-h_{i}^{\circ}(T)=\int_{P^{\circ}}^{P}\left[\frac{1}{\rho}-\frac{T}{\rho^{2}}\left(\frac{\partial \rho}{\partial T}\right)_{P}\right]_{T} d P$

$C_{p}(T, \rho)-C_{v}^{\circ}(T)=-\int_{\rho^{\circ}}^{\rho}\left[\frac{T}{\rho^{2}}\left(\frac{\partial^{2} P}{\partial T^{2}}\right)_{\rho}\right]_{T} d \rho+\frac{T}{\rho^{2}} \frac{\left(\frac{\partial^{2} P}{\partial T^{2}}\right)_{\rho}}{\left(\frac{\partial P}{\partial \rho}\right)_{T}}$

and are exact relations derived from the Maxwell's laws. Standard state properties are obtained using the databases developed by Gordon and McBride [31] and Kee et al. [32].

\subsection{Transport properties}

At supercritical pressures, classical methods to determine transport properties do not apply. Mixing between dense and light fluids depend on molecular interactions, which differ from classical two-phase flow processes. Hence, an accurate formalism for the evaluation of transport coefficients is required. Here, molecular transport properties are evaluated in a manner analogous to the thermodynamic properties. Viscosity and thermal conductivity are obtained using the extended corresponding states methodologies developed by Ely and Hanley [33,34]. Mass and thermal diffusion coefficients are obtained using methodologies from the work of Bird et al. [35], Hirschfelder et al. [36] and Takahashi [37]. This approach can handle general systems where multicomponent and/or preferential diffusion processes are present. 


\subsection{Chemical kinetics and source term closure}

For the present study, a finite-rate hydrogen-oxygen kinetics is employed using the nine species $\left(\mathrm{H}_{2}, \mathrm{O}_{2}, \mathrm{OH}, \mathrm{H}_{2} \mathrm{O}, \mathrm{H}, \mathrm{O}, \mathrm{HO}_{2}, \mathrm{H}_{2} \mathrm{O}_{2}\right.$, $\mathrm{N}_{2}$ ), 19-step mechanism developed by of Ó-Conaire et al. [38]. One of the main objectives of this work is to study the flame structure of oxygen-hydrogen at elevated pressure. Hence the flame is completely resolved on the grid and no turbulent closure is required.

\subsection{Numerical approach}

The governing system is discretized on a staggered grid in generalized curvilinear coordinates. This formulation provides nondissipative, spectrally clean, damping characteristics and discrete conservation of mass, momentum, and total-energy. Integration is performed using a unique dual-time multistage scheme with a generalized all-Mach-number preconditioning methodology that optimally treats convective, diffusive, geometric, and source term anomalies in a unified manner. The implicit formulation is A-stable, which allows one to set the physical timestep based solely on accuracy considerations. The scheme accommodates any arbitrary equation of state. The algorithm has been optimized to provide excellent parallel scalability attributes using a distributed multiblock domain decomposition with generalized connectivity. Inflow and outflow conditions are treated using the method of characteristics $[39,40]$.

\section{Flame structure analysis}

It was shown in the introduction that the laminar flamelet assumption applies to $\mathrm{H}_{2}-\mathrm{O}_{2}$ combustion in rocket engines since the characteristic timescale of turbulence $\left(\tau_{t} \approx 1 \mu \mathrm{s}\right)$ [19] is larger than the characteristic timescale of chemistry $\left(\tau_{c} \approx 0.01 \mu \mathrm{s}\right)$. High frequency acoustic oscillations can be coupled to combustion also $[41,42]$. The highest frequencies are commonly of the order of $10^{4} \mathrm{~Hz}$, which implies that the acoustic characteristic time $\tau_{\text {acoustic }}>100 \mu \mathrm{s}$ and that the steady state assumption remains valid.

Consequently, the study of flame structure can be based on a classical counter-flow flame analysis.

\subsection{Present approach}

Figure 1 shows a sketch of the configuration, where a laminar fuel rich jet is opposed to a laminar oxidizer rich jet with a diffusion flame stabilized near the stagnation point. The strain applied to the flame mimics the effect of a turbulent eddy forcing the flow toward the flame. The shape of the numerical domain is defined using the theory of potential flows. Based on this theory, wall profiles can be determined following the streamline equations (Fig. 1b). The special shape of the computational domain allows one to optimize grid quality and the accuracy of the boundary conditions. The position of point A (Fig. 1c) is arbitrary. Point B is on the streamline that passes through point $A$ (see below for the equation of streamlines) and only its $y$-coordinate is arbitrary. Between points $B$ and $C$, a second order polynomial function is used to get a tangent at $y=0$ and an inflection point in $\mathrm{B}$.

The mesh spacing is such that the flame zone is resolved across at least 25 nodes. The total grid size is 230,000 cells. Global scaling of the grid is adapted as a function of pressure and strain rate to enforce the resolution constraint.

The boundary condition specifications are based on three assumptions:

1. The flow is an opposed-jet potential flow with stream lines describe by: $x y=$ constant and $V / y=-U / x$

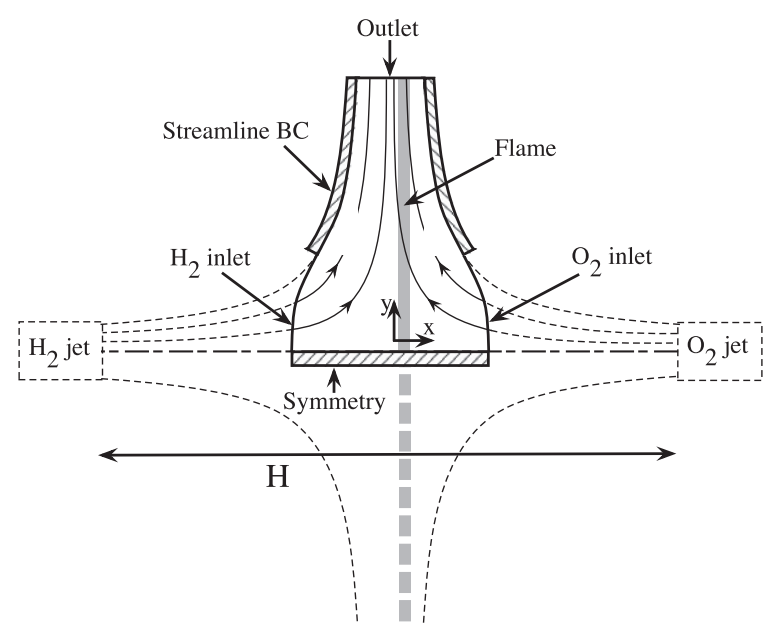

(a)

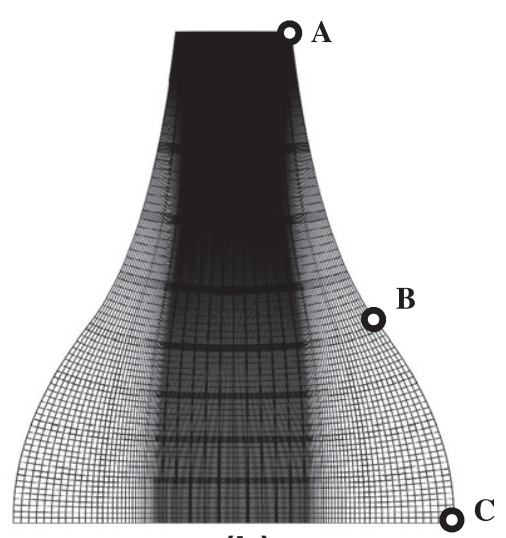

(b)

Fig. 1. Computational domain used for the two-dimensional counter-flow flame $(H$ is the distance between inlets), (a) the actual computational domain, and (b) the computational grid.

2. The stagnation point is on the centerline of the configuration, where $\rho_{\mathrm{H}_{2}}\left(U_{\mathrm{H}_{2}}(x)\right)^{2}=\rho_{\mathrm{O}_{2}}\left(U_{\mathrm{O}_{2}}(-x)\right)^{2}$ (for a given axial position $x>0$ )

3. The overall strain rate is defined as: $a=\frac{\left|U_{H_{2}}^{i n j}\right|+\left|U_{O_{2}}^{i n j}\right|}{H}=$ $\frac{\left|U_{\mathrm{H}_{2}}(x)\right|+\left|U_{\mathrm{O}_{2}}(-x)\right|}{2 x}$ (for a given axial position $x>0$ )

where $U$ and $V$ are the velocities in $x$ and $y$ directions, respectively. The spatial origin is centered on the stagnation point, see Fig. $1 \mathrm{c}$. The superscript ${ }^{i n j}$ refers to inlet quantities, the subscripts $\mathrm{H}_{2}$ and $\mathrm{O}_{2}$ refer to the hydrogen and oxygen inlets respectively, $\rho$ is the density and $H$ is the distance between inlets.

These assumptions result in the following set of equations characterizing inlet conditions:

for $x<0, \forall y$ :

$$
\begin{aligned}
& U_{O_{2}}(x, y)=-\frac{2 a x}{1+\sqrt{\rho_{O_{2}}^{i n j} / \rho_{H_{2}}^{i n j}}} \\
& V_{O_{2}}(x, y)=\frac{2 a y}{1+\sqrt{\rho_{O_{2}}^{i n j} / \rho_{H_{2}}^{i n j}}}
\end{aligned}
$$

for $x>0, \forall y$ : 
Table 1

Boundary description for the counter-flow flame configuration.

\begin{tabular}{lll}
\hline Inlets & Outlet & $\begin{array}{l}\text { Wall (streamline BC in } \\
\text { Fig. 1b) }\end{array}$ \\
\hline $\begin{array}{l}\text { Zero gradient } \\
\begin{array}{l}\text { Imposed velocity and } \\
\text { temperature }\end{array}\end{array}$ & $\begin{array}{l}\text { Zero gradient } \\
\text { Imposed } \\
\text { pressure }\end{array}$ & Adiabatic slip wall \\
\hline
\end{tabular}

Table 2

The injection conditions of the present study cases $\left(T_{O_{2}}^{c}=155 \mathrm{~K}\right.$ and $P_{O_{2}}^{c}=50.4 \mathrm{bar}$ ).

\begin{tabular}{|c|c|c|c|c|c|}
\hline Objective & $\begin{array}{l}\text { Case } 1 \\
\text { Validation }\end{array}$ & $\begin{array}{l}\text { Case } 2 \\
\text { Strain rate effects }\end{array}$ & $\begin{array}{l}\text { Case } 3 \\
\text { Pressure effects }\end{array}$ & $\begin{array}{l}\text { Case } 4 \\
\text { Temperature effects }\end{array}$ & $\begin{array}{l}\text { Case } 5 \\
\text { Real-fluid effects }\end{array}$ \\
\hline$T_{H 2}^{i n j}(\mathrm{~K})$ & 300 & 295 & 295 & 295-500 & 295 \\
\hline$T_{O 2}^{i n j}(\mathrm{~K})$ & 300 & 120 & 120 & 120-500 & 154 \\
\hline$P$ (bar) & 50 & 70 & 53-90 & 70 & 47 and 53 \\
\hline$a\left(\mathrm{~s}^{-1}\right)$ & $2 \times 10^{3}$ & $5 \times 10^{4}-5 \times 10^{6}$ & $10^{5}$ & $10^{5}$ & $10^{5}$ \\
\hline$\rho_{H 2}^{i n j}\left(\mathrm{~kg} / \mathrm{m}^{3}\right)$ & 3.9 & 5.6 & $4.0-7.2$ & $5.6-3.3$ & $3.8-4.2$ \\
\hline$\rho_{O 2}^{i n j}\left(\mathrm{~kg} / \mathrm{m}^{3}\right)$ & 66 & 1112 & $1098-1124$ & $1112-53$ & $245-587$ \\
\hline \multicolumn{6}{|c|}{ Oxidizer side: $Y_{\mathrm{O}_{2}}=1$ and fuel side: $Y_{\mathrm{H}_{2}}=1$} \\
\hline
\end{tabular}

$\begin{aligned} U_{H_{2}}(x, y) & =-\frac{2 a x}{1+\sqrt{\rho_{H_{2}}^{i n j} / \rho_{O_{2}}^{i n j}}} \\ V_{H_{2}}(x, y) & =\frac{2 a y}{1+\sqrt{\rho_{H_{2}}^{i n j} / \rho_{O_{2}}^{i n j}}}\end{aligned}$

Boundary condition types used for this computations are given in Table 1.

The conditions of the different computed cases are described Table 2. The objectives of the present study are to determine the relevant tabulation parameters at the conditions of interest while simultaneously investigating non-linear pressure effects on the modeling approach. The first step in this process (Case 1) is to validate the detail computation approach taken here against the reference data of Ribert et al. [17]. Cases 2-4 are then dedicated to the study of strain, pressure and temperature effects on the flame structure. Parametric ranges have been selected to bracket the conditions of interest: $P=70$ bar, $a \approx 9 e^{5} s^{-1}, T_{\mathrm{H}_{2}}=295 \mathrm{~K}$ and $T_{O_{2}}=120 \mathrm{~K}^{1}$

After establishing the dependencies, the purpose of Case 5 is to investigate real-fluid effects on the flame structure. For this case, the oxygen temperature $(T=154 \mathrm{~K})$ is slightly lower that the critical temperature $\left(T_{\mathrm{O}_{2}}^{c}=155 \mathrm{~K}\right)$. Then by varying the pressure by a few bars around the critical pressure $\left(P_{O_{2}}^{c}=50.4 \mathrm{bar}\right)$, it is possible to obtain transcritical oxygen $(P=53$ bar) or gaseous oxygen ( $P=47 \mathrm{bar}$ ). Hence, the differences in the flame structure only depend on non-idealities of high pressure effects.

For clarity, a schematic of the locations of the flames in the $P-T$ diagram of oxygen is presented in Fig. 2 for Cases 4 and 5.

\subsection{Case 1: flow topology and validation}

The first step in this study was to test the capability of the solver to capture the laminar flame structure obtained in the detailed calculation of Ribert et al. [17]. This reference work was carried out using a detailed combustion solver for laminar flows (DMCFs) [43] designed to study counter-flow diffusion flames for general fluids over the entire regime of thermodynamic states (subcritical to

\footnotetext{
${ }^{1}$ In the rocket engine where the model will be used, the maximum strain rate experienced by the flame can be estimated as: $a_{\max } \approx\left(U_{\mathrm{H}_{2}}-U_{\mathrm{O}_{2}}\right) / e \approx 9 \times 10^{5} \mathrm{~s}^{-1}$. $U_{\mathrm{H}_{2}}(=353 \mathrm{~m} / \mathrm{s})$ and $U_{\mathrm{O}_{2}}(=14 \mathrm{~m} / \mathrm{s})$ are the mean velocities of hydrogen and oxygen flows issuing for the injector and $e(=0.38 \mathrm{~mm})$ is the thickness of the injector lip.
}

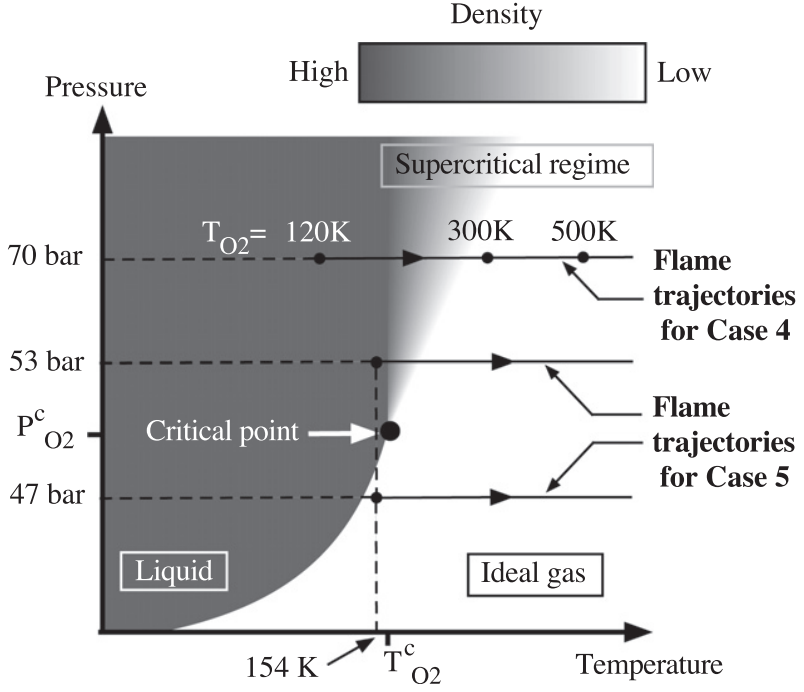

Fig. 2. Cases 4 and 5 : locations of the different flames in the oxygen $P-T$ diagram $\left(T_{\mathrm{O}_{2}}^{c}=155 \mathrm{~K}\right.$ and $P_{\mathrm{O}_{2}}^{c}=50.4$ bar $)$.

supercritical conditions). Hydrogen-oxygen chemistry was modeled using the mechanism from Li et al. [44]. $\mathrm{H}_{2} / \mathrm{O}_{2}$ flame structure was investigated at pressures ranging from 1 to $25 \mathrm{MPa}$ and with oxygen injection temperatures of 100 and $300 \mathrm{~K}$.

The main differences between the approach of Ribert and the present study are presented in Table 3 .

Figure 3 presents the temperature field and the streamlines of the flow in the counterflow domain. The present setup allows one to reproduce correctly the flow topology of a laminar opposed-jet configuration. Boundary conditions are well controlled through the set of equations presented previously, resulting in fast convergence rates. Grid resolution can also be accurately adapted to flow conditions in order to resolve properly strong gradients. Figure 4 presents the density fields under the conditions of Cases 1 and 2. This figure shows that the grid resolution must adapt to maintain the required spatial resolution.

Figure 5 presents a direct comparison between the present study and the results obtained by Ribert et al. [17] for density, temperature and species profiles across the flame front. Good agreements are obtained. These results indicate that the thermodynamic 
Table 3

Differences in the modeling approaches between the work of Ribert et al. [17] and the present study.

\begin{tabular}{|c|c|c|}
\hline & Ribert et al. [17] & Present study \\
\hline Equation of state & $\begin{array}{l}\text { Soave-Redlick-Kwong } \\
\text { [1] }\end{array}$ & Peng-Robinson [29] \\
\hline Chemical scheme & Li et al. [44] & Ó-Conaire et al. [38] \\
\hline $\begin{array}{l}\text { Viscosity and thermal } \\
\text { conductivity }\end{array}$ & Chung et al. [45] & $\begin{array}{l}\text { Ely and Hanley } \\
{[33,34]}\end{array}$ \\
\hline Resolution method & $\begin{array}{l}\text { Time-marching and } \\
\text { Newton } \\
\text { Iteration techniques } \\
\text { [43] }\end{array}$ & $\begin{array}{l}\text { Dual time stepping } \\
\text { [30] }\end{array}$ \\
\hline Grid & Global adaptive grid & $\begin{array}{l}\text { Stretched } \\
\text { curvilinear grid }\end{array}$ \\
\hline
\end{tabular}

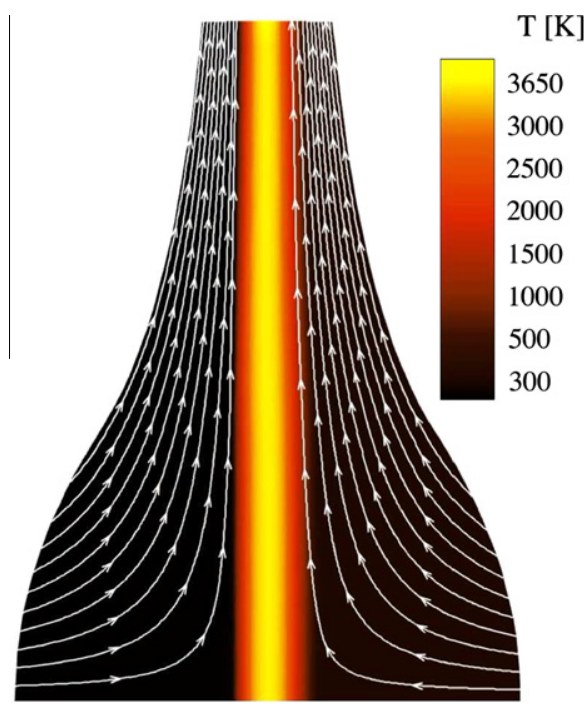

Fig. 3. Temperature field and the flow topology of a typical counterflow flame.

evaluation scheme used in the present study, as well as the cubic equation of state, give satisfactory results. Based on this, our solver appears to be appropriate to investigate the effects of flow conditions on the flame structure.

\subsection{Case 2: effect of strain}

The aim of this second set of tests is to study strain rate effects on the flame structure. The flame robustness to strain at the conditions of interest is studied, to determine if variations in scalar dissipation rate must be taken into account in the tabulation.

Figure 6 shows the temperature profiles in mixture fraction space $Z_{\mathrm{H}}$, and in physical space as well, for different strain rates at the conditions of interest $\left(T_{\mathrm{O}_{2}}=120 \mathrm{~K}, T_{\mathrm{H}_{2}}=295 \mathrm{~K}\right.$ and $P=70$ bar). Note that the present flame is composed of species with very different diffusion coefficients, but the mixture fraction is based on $H$ atoms to ensure it remains a passive scalar [28]:

$Z_{\mathrm{H}}=W_{\mathrm{H}}\left(2 \frac{Y_{\mathrm{H}_{2}}}{W_{\mathrm{H}_{2}}}+\frac{Y_{\mathrm{H}}}{W_{\mathrm{H}}}+2 \frac{Y_{\mathrm{H}_{2} \mathrm{O}}}{W_{\mathrm{H}_{2} \mathrm{O}}}+\frac{Y_{\mathrm{OH}}}{W_{\mathrm{OH}}}+\frac{Y_{\mathrm{HO}_{2}}}{W_{\mathrm{HO}_{2}}}+2 \frac{Y_{\mathrm{H}_{2} \mathrm{O}_{2}}}{W_{\mathrm{H}_{2} \mathrm{O}_{2}}}\right)$

In Fig. 6a, one can observe that all temperature profiles collapse on the same curve for strain rates less than or equal to $10^{6} \mathrm{~s}^{-1}$. Under the infinitely fast chemistry assumption, it possible to analytically show that the heat release rate $\dot{Q}_{s}$ of a strained flame scales as $\sqrt{a}$ $[28]^{2}$ By definition:

2 This result has been observed in the present study and in the work of Ribert et al. [17] and thus are not presented here for sake of conciseness.

$$
\begin{aligned}
& \dot{Q}_{s}=\int_{-\infty}^{+\infty} \dot{\omega}_{T} d x \\
& \dot{\omega}_{T}=\sum_{i=1}^{N_{s}} h_{i}^{\circ} W_{i} \dot{\omega}_{i}
\end{aligned}
$$

where $h_{i}$ o and $\dot{\omega}_{i}$ are the formation enthalpy and the molar production rate of the $i$ th species respectively.

Diffusion fluxes taking heat away from the flame also scale as $\sqrt{a}$ [28]. Consequently, both source and sink effects balance each other exactly, which explains why the maximum temperature remains constant. When the chemical and diffusion timescales become the same order of magnitude (as the strain rate increases), the infinitely fast chemistry assumption vanishes and heat release no longer compensates the heat losses. Thus,the maximum temperature decreases. This effect is shown in Fig. $6 \mathrm{~b}$ where the maximum flame temperature is almost constant for $a<10^{6} \mathrm{~s}^{-1}$ and close to the equilibrium temperature, but decreases for higher strain rates $\left(a>10^{6} \mathrm{~s}^{-1}\right)$.

In physical space, an increase in strain rate induces a decrease in flame thickness. An estimate of the flame thickness $\left(\delta_{f l m}\right)$ can be derived from the scalar dissipation rate definition:

$\delta_{f l m} \approx\left(\frac{1}{|\nabla Z|}\right)_{Z=Z_{s t}}=\sqrt{\frac{2 D_{s t}}{\chi_{s t}}} \propto 1 / \sqrt{P a}$,

where $Z_{s t}, D_{s t}$ and $\chi_{s t}$ are the mixture fraction, molecular diffusion coefficient, and scalar dissipation rate at the stoichiometric point.

In the present work, the flame thickness follows this trend and the same observation was made by Ribert et al. [17].

Analysis of these results verifies that the infinitely fast chemistry assumption is valid for the range of strain rates of interest $\left(a<9 \times 10^{5} \mathrm{~s}^{-1}\right)$. Hence, a chemistry tabulation does not require that the strain rate be taken into account.

\subsection{Case 3: effect of pressure}

In liquid rocket engines, small pressure oscillations may perturb the flow dynamics or flame leading to combustion instabilities $[41,42]$. Under certain circumstances, acoustic waves may have an effect on mixing, mass flow-rate, combustion, etc., and can result in a modulation of the heat release and subsequently a new pressure perturbation. Coupling may occur and sustained pressure oscillations may develop in the combustor. Combustion instabilities can have severe consequences on the efficiency of the burner and can lead to its destruction. Such instabilities are still not fully understood and active research is currently dedicated to this field (see for example [46-48]). In these investigations, the amplitude of pressure oscillations never goes over $30 \%$ of the mean pressure. Hence, pressure effects on the flame structure were investigated here in the range 53 - 90 bar (the lowest pressure must be higher than the critical pressure of oxygen $P_{\mathrm{O}_{2}}^{c}=50.4$ bar).

Figure 7 presents the impact of pressure on the flame structure in both physical and mixture fraction space. The first observation is that the maximum flame temperature increases with pressure (Fig. 7a). However, in the range of interest, the variation of the maximum temperature is about $100 \mathrm{~K}$ which represents a discrepancy of about 3\% with respect to the flame temperature at 70 bar. Another effect is the modification of the flame thickness. This tendency is predicted by asymptotic analysis as shown in Section 3.3, Eq. (17), and it was verified that the flame thickness is pressure dependent via the relation: $\delta_{f l m} \propto 1 / \sqrt{P}$. A similar derivation shows that for infinitely fast chemistry, the heat release rate follows the relation: $\dot{Q}_{s} \propto \sqrt{P}$ [28]. This result was observed in the present study, and is a classical trend for fast chemical systems.

In mixture fraction space, temperature profiles and mass-fraction distributions almost collapse on the same curve (Fig. 7b and 


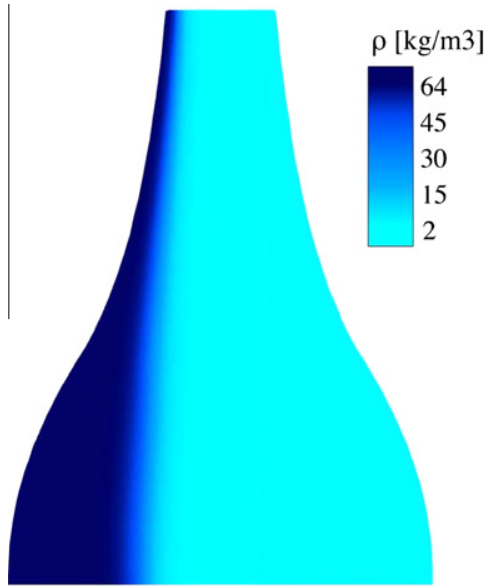

(a)

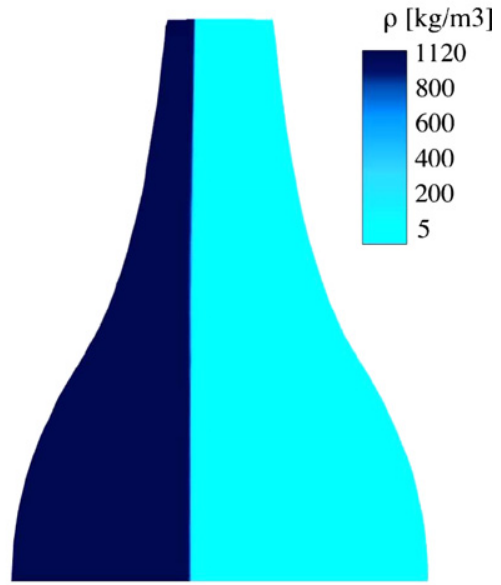

(b)

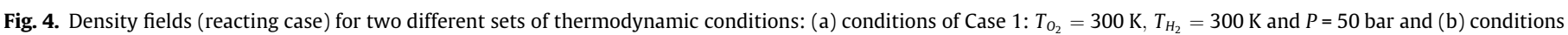
of Case 2: $T_{\mathrm{O}_{2}}=120 \mathrm{~K}, T_{\mathrm{H}_{2}}=295 \mathrm{~K}$ and $P=70$ bar.

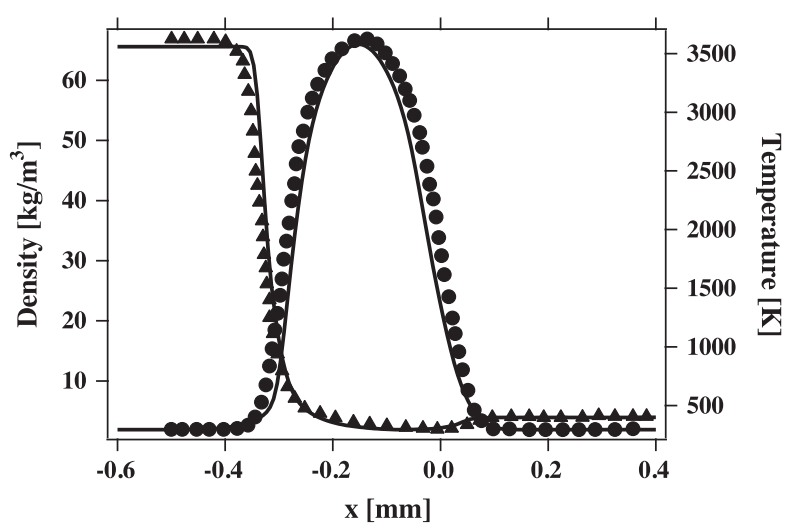

(a)

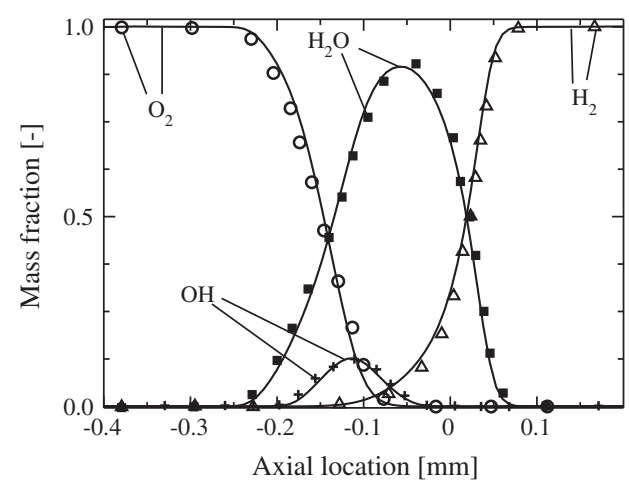

(b)

Fig. 5. Flame structure validation. (a) Density and temperature profiles and (b) major species profiles. $T_{\mathrm{O}_{2}}=T_{\mathrm{H}_{2}}=300 \mathrm{~K}, P=50 \mathrm{bar}$ and $a=2000 \mathrm{~s}^{-1}$. Symbols: reference calculation of Ribert et al. [17], lines: present study.

c). This shows that only one flame is required to represent temperature and species profiles over a wide range of pressures. For the pressure range considered here, the error is less than $3 \%$.

Another aspect of the effect of pressure is shown in Fig. 8 where the distribution of thermodynamic and transport properties are presented in mixture-fraction space. In this figure, one can observe that pressure effects are moderate in the flame region $\left(Z_{H} \geqslant 10^{-2}\right)$.
Thus, for these values of mixture fraction, a direct tabulation of the thermodynamic and transport parameters can be considered. However, in the trans-critical region, where the heat capacity reaches a local maximum, some discrepancies appear due to high-pressure non-idealities.

\subsection{Case 4: effect of temperature}

Temperature effects occur when mixture temperature changes by processes other than mixing. In rocket engines, hot walls may increase the temperature of the reactants. Figure 9 shows the impact of temperature on flame structure in both physical and mixture fraction space. When the temperature of oxygen or hydrogen is increased, the maximum temperature of the flame increases. Between the four cases considered here, the maximum flame temperature only changes by $40 \mathrm{~K}$, which represents about $1 \%$ of variation with respect to the reference flame. This trend was also observed by Ribert et al. [17]. One may note that this result does not agree with the relation: $T_{a d}=Z_{s t} T_{F}^{0}+\left(1-Z_{s t}\right) T_{O}^{0}+Q / C_{p} Y_{F}^{0} Z_{s t}$, which gives the maximum temperature $\left(T_{a d}\right)$ in an ideal-gas diffusion flame. This relation is derived for a single reaction, unity Lewis numbers, and constant capacity $C_{p}$. Non-idealities caused by high pressure conditions and complex chemistry are most likely responsible for this difference. Another observation is that the flame structure in the physical space is not modified significantly by changing the temperature of the oxygen or hydrogen streams (see Fig. 9a). The same observation is made for species.

In mixture fraction space, temperature profiles are close to each other in the high temperature region (Fig. 9b). Some differences are observed when the mixture fraction goes to its limits $(Z \rightarrow 1$ and $Z \rightarrow 0$ ). These differences have small impact on the flame structure in physical space as shown in Fig. 9a. In addition, species profiles in mixture space are not affected by temperature changes (Fig. 9c). These results point out that temperature effects are negligible on flame structure, as long as these variations remain small, which is the case close to the injector in the context of rocket combustion. Further downstream of the injector however, conduction processes and the long residence time of the oxygen in hot product regions induce large temperature variations that may exceed the critical temperature $T_{0_{2}}^{c}$ (the Lewis number of oxygen is around 8 in the core of the jet: $L e_{\mathrm{O}_{2}} \approx 8$ ). Under these conditions, density, thermodynamic properties and transport parameters will dramatically change. This aspect has not been investigated in detail by Ribert 


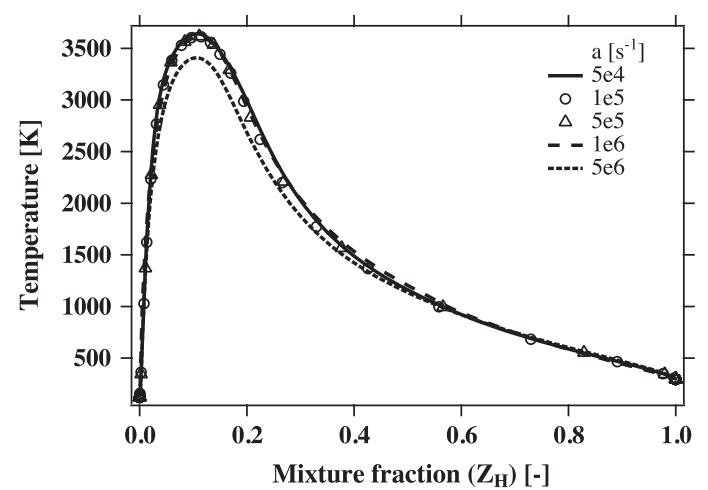

(a)

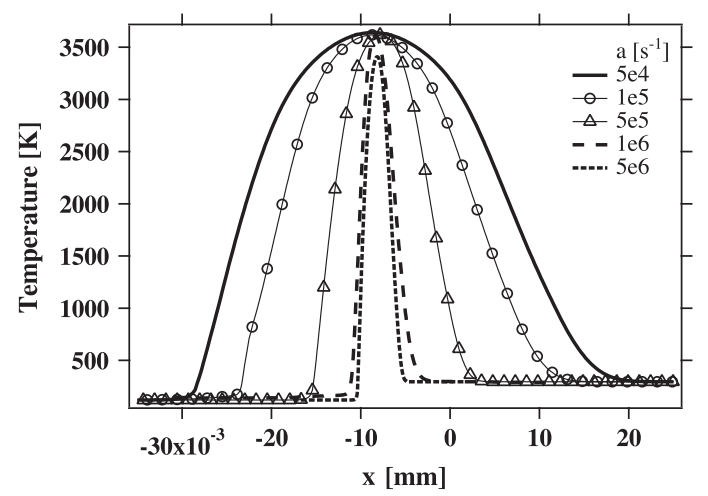

(b)

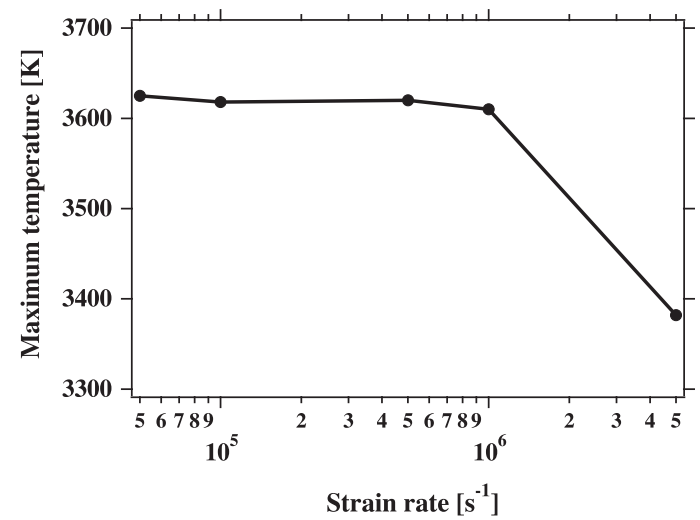

(c)

Fig. 6. Strain rate effect on the $\mathrm{H}_{2} / \mathrm{O}_{2}$ counter flow flame. (a) Temperature distribution in mixture fraction $\left(Z_{H}\right)$ space, (b) temperature distribution in physical space and (c) maximum flame temperature. $\left(T_{\mathrm{O}_{2}}=120 \mathrm{~K}, T_{\mathrm{H}_{2}}=295 \mathrm{~K}\right.$ and $P=70$ bar).

et al. [17], however the present results shown in Fig. 10 are in contradiction with the observation made in [17] that variations of oxygen temperature (from $300 \mathrm{~K}$ to $100 \mathrm{~K}$ ) have only a limited impact.

Figure 10a shows that an increase of $170 \mathrm{~K}$ in the oxygen inlet temperature induces strong variation in density. When the inlet temperature is below the critical temperature of oxygen $\left(T_{O_{2}}^{c}=155 \mathrm{~K}\right)$, the oxygen behaves as a dense fluid. When $T_{\mathrm{O}_{2}}>T_{\mathrm{O}_{2}}^{c}$, the oxygen has a gas-like density. A schematic of the locations of these flames in the $P-T$ diagram of oxygen is presented in Fig. 2. This trend can be illuminated more accurately considering the compressibility factor:

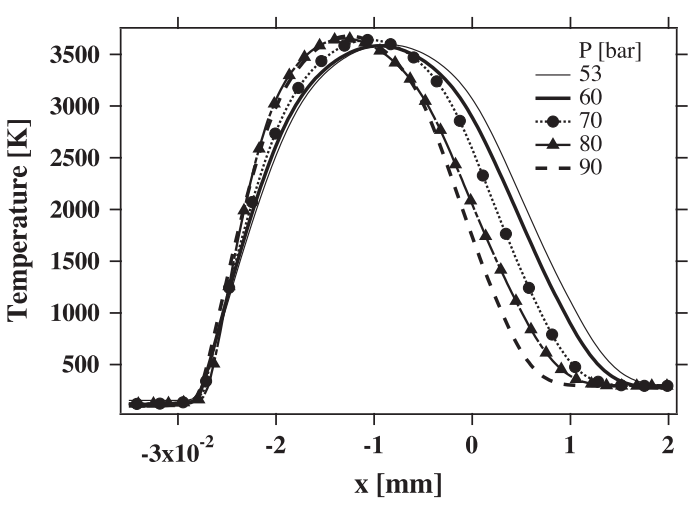

(a)

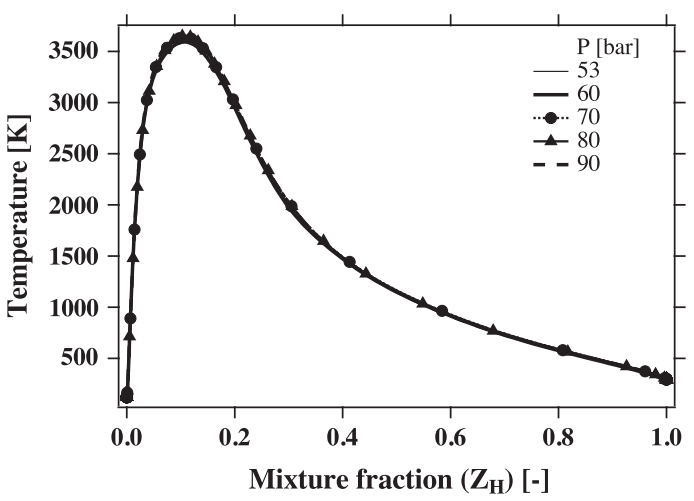

(b)

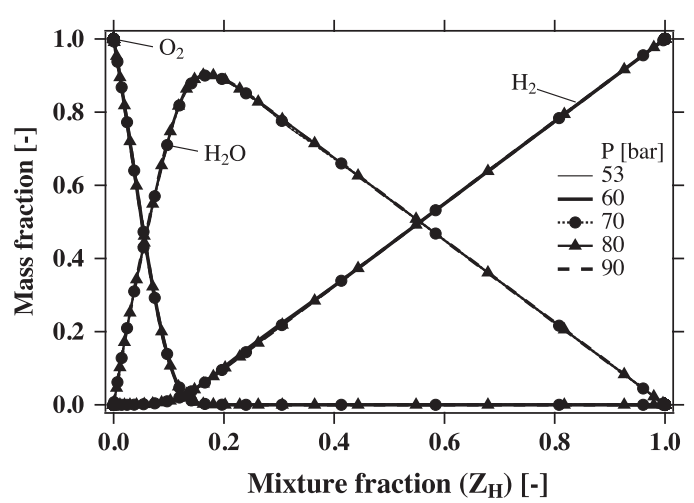

(c)

Fig. 7. Pressure effect on the $\mathrm{H}_{2} / \mathrm{O}_{2}$ counter flow flame. (a) Temperature distribution in physical space, (b) and (c) temperature distribution and mass fractions of principal species in mixture fraction space. $\left(T_{\mathrm{O}_{2}}=120 \mathrm{~K}, T_{\mathrm{H}_{2}}=295 \mathrm{~K}\right.$ and $\left.a=10^{5} \mathrm{~s}^{-1}\right)$.

$Z c=\frac{P V}{R T}$

The compressibility factor is an indicator of how far a fluid is from ideal-gas properties: when $Z c=1$ the fluid can be considered as an ideal gas, and when $Z c \ll 1$ the fluid has liquid-like properties and its thermodynamic conditions cannot be described by an ideal equation of state.

The compressibility factor across the flame front is presented in Fig. 10b. For sub-critical temperatures of the oxygen $\left(T_{O_{2}}=120 \mathrm{~K}\right)$, the compressibility factor in the oxidizer stream is $Z c=0.2$. This indicates that oxygen has liquid-like properties and non-linear effects are expected when the mixture is heated-up in the vicinity of 


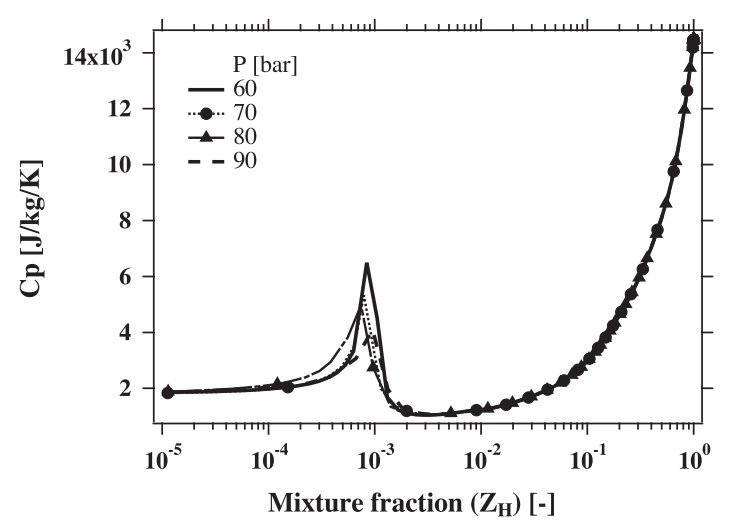

(a)

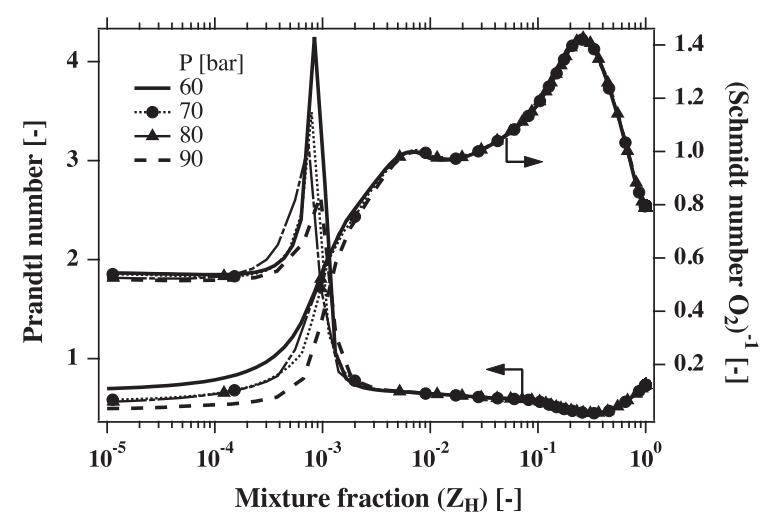

(b)

Fig. 8. Pressure effect on thermodynamic and transport properties: (a) Heat capacity of the mixture ( $\mathrm{Cp}$ ) and (b) Prandtl number and inverse of Schmidt number of oxygen $\left(1 / S_{c}^{O_{2}}\right)$ in mixture-fraction space. $\left(T_{\mathrm{O}_{2}}=120 \mathrm{~K}, T_{\mathrm{H}_{2}}=295 \mathrm{~K}\right.$ and $\left.a=10^{5} \mathrm{~s}^{-1}\right)$.

the flame front. For super-critical values of the temperature $\left(T_{\mathrm{O}_{2}}=300 \mathrm{~K}\right.$ and $T_{\mathrm{O}_{2}}=500 \mathrm{~K}$ ), the oxygen can be viewed as an ideal gas. In addition, in the flame region $\left(Z_{H} \geqslant 10^{-2}\right)$, the idealgas behavior is recovered due to high temperatures. Figure $10 \mathrm{c}$ presents the heat capacity at constant pressure across the flame and reveals one aspect of the non-ideal effect experienced by the mixture. For oxygen injection temperatures above the critical temperature $\left(T_{\mathrm{O}_{2}}=300 \mathrm{~K}\right.$ and $\left.T_{\mathrm{O}_{2}}=500 \mathrm{~K}\right)$, the heat capacity $\mathrm{Cp}$ of the mixture follows the ideal-gas law. Note that in the flame region $\left(Z_{H} \geqslant 10^{-2}\right), C p$ is fairly insensitive to variations of inlet temperatures. For sub-critical injection temperatures $\left(T_{O_{2}}=120 \mathrm{~K}\right)$, the heat capacity is subject to a sharp peak close to the density jump. This real-fluid effect has a noticeable impact on the overall behavior of the flow since high $C p$ values tend to prevent temperature diffusion in the dense oxygen stream.

\subsection{Case 5: real-fluid effects}

To investigate the impact of real-fluid effects due to high pressure, inlet temperatures were fixed and thermodynamic conditions were varied by changing the pressure. In the present study, the inlet temperature of oxygen is set at $154 \mathrm{~K}$, which is one Kelvin below the critical temperature $\left(T_{\mathrm{O}_{2}}^{c}=155 \mathrm{~K}\right)$, and the injection temperature of hydrogen is kept at $295 \mathrm{~K}$. One flame is studied at 47 bar, where the oxygen is injected as a gas and does not experience transcritical effects. A second flame is studied at $53 \mathrm{bar}$,

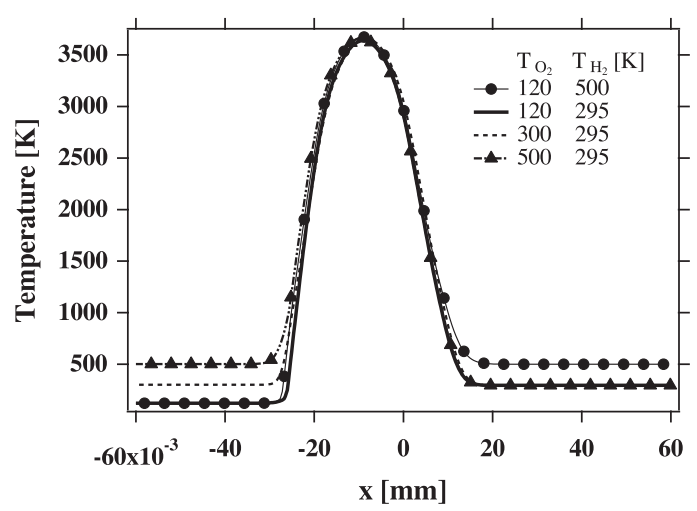

(a)

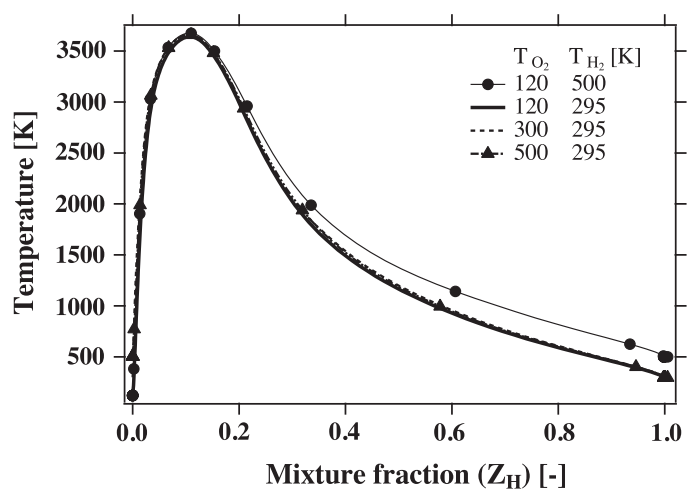

(b)

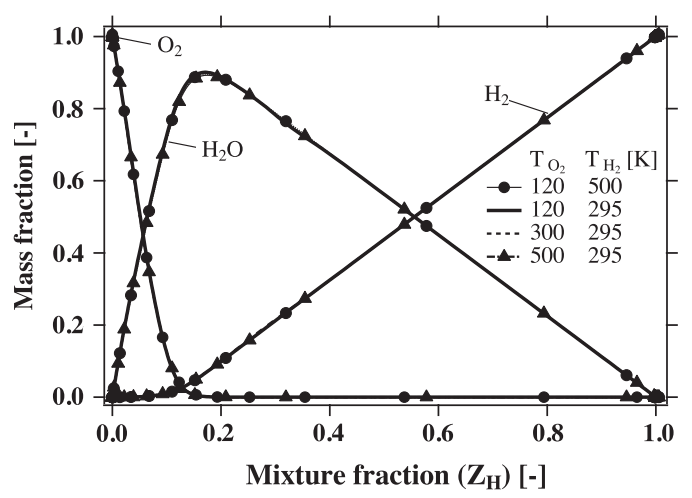

(c)

Fig. 9. Temperature effect on the $\mathrm{H}_{2} / \mathrm{O}_{2}$ counter flow flame. (a) Temperature distribution in physical space, (b) and (c) temperature distribution and mass fractions of principal species in mixture fraction space. ( $P=70$ bar and $a=10^{5} \mathrm{~s}^{-1}$ ).

where the oxygen is injected as a compressed liquid in the transcritical regime. The locations of these two flames in the $P-T$ diagram for oxygen are shown in Fig. 2.

Temperature and density in physical and mixture-fraction spaces are shown in Fig. 11. In physical space, the temperature profile at 53 bar is slightly narrower than the one at 47 bar due to the effect of pressure on the flame thickness. This effect was observed previously in Section 3.4. The maximum temperature of the two flames are the same. The main difference can be observed in the density profiles. For the transcritical case $(P=53 \mathrm{bar})$, the injection density of the oxidizer is $587 \mathrm{~kg} / \mathrm{m}^{3}$ whereas the ideal-gas flame $(P=47 \mathrm{bar})$ is fed with a $245 \mathrm{~kg} / \mathrm{m}^{3}$ oxygen stream. This difference is a direct consequence of the location of these flames in the $P$ - Tdiagram. 


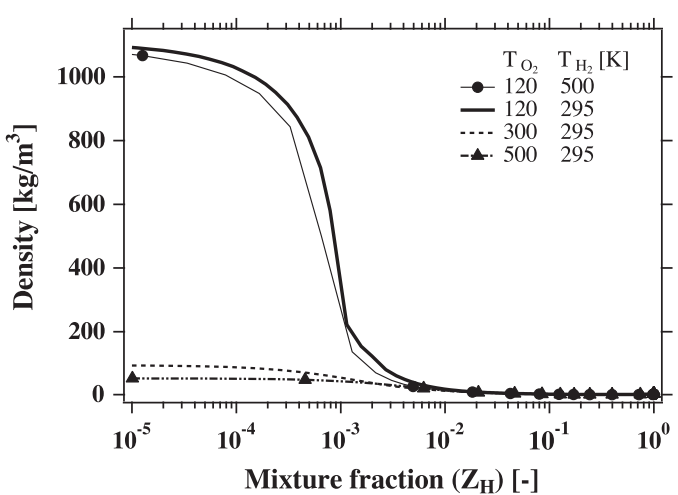

(a)

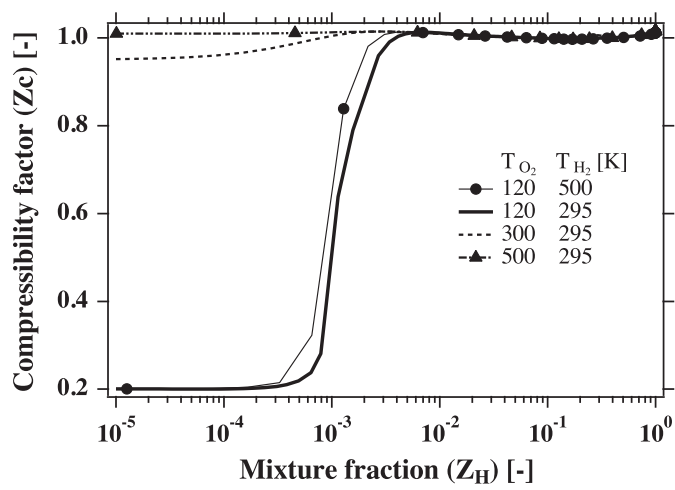

(b)

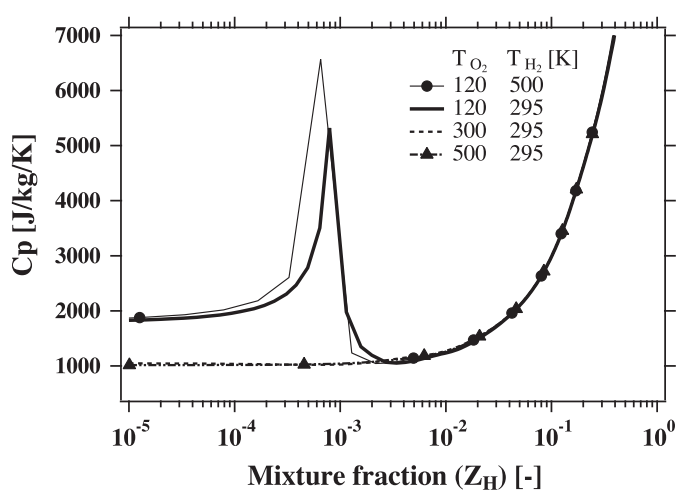

(c)

Fig. 10. Temperature effect on thermodynamic properties: (a) Density $(\rho)$, (b) compressibility factor $(Z c)$ and (c) heat capacity of the mixture $(C p)$ in mixturefraction space. $\left(P=70\right.$ bar and $\left.a=10^{5} \mathrm{~s}^{-1}\right)$.

Figure 11b shows the temperature distribution across the two flames in mixture-fraction space. For clarity, the temperature difference indicated in percent has been added to the plot. Non-ideal effects are observed for mixture fraction values around $Z \approx 10^{-3}$. The difference between the two temperature curves is about $16 \%$. This shows that near the critical point, a variation of $11 \%$ of the pressure implies a $16 \%$ variation of the temperature. These differences might be considered negligible, but they appear in a region where non-linear effects are significant. This implies they have to be taken into account in the modeling framework. For conciseness, species profiles are not shown here since no significant impact of non-ideal effects were observed.

Real fluid effects are further investigated by considering thermodynamic and transport properties. Figure 12 shows the heat

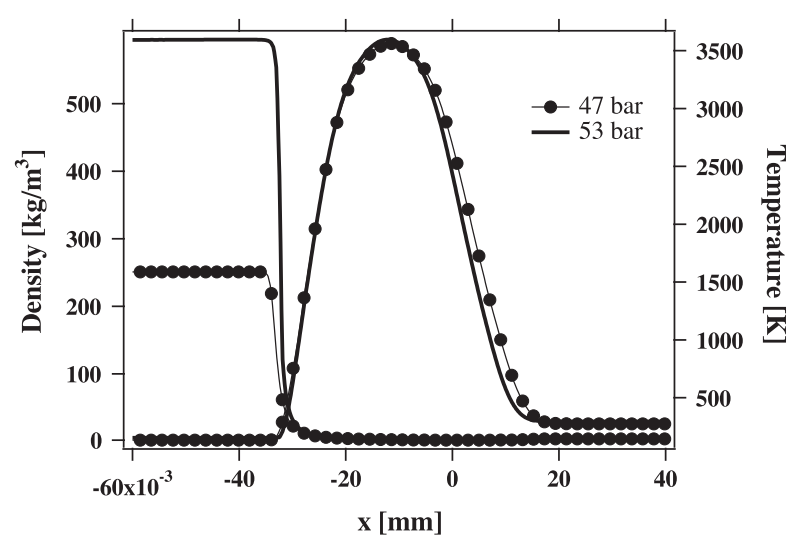

(a)

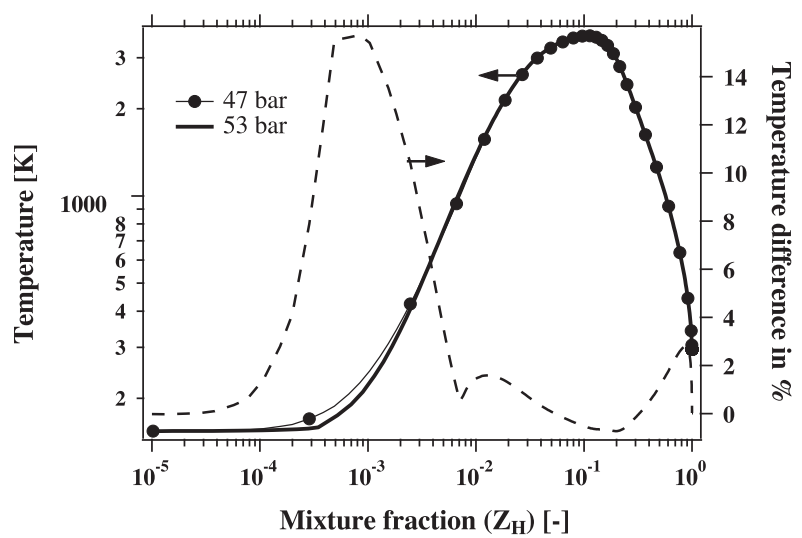

(b)

Fig. 11. Real fluid effects in the $\mathrm{H}_{2} / \mathrm{O}_{2}$ counter flow flame. (a) Temperature and density distributions in physical space and (b) temperature distribution in mixture fraction space. $\left(T_{\mathrm{O}_{2}}=154 \mathrm{~K}, T_{\mathrm{H}_{2}}=295 \mathrm{~K}\right.$ and $\left.a=10^{5} \mathrm{~s}^{-1}\right)$.

capacity at constant pressure $(C p)$ and the thermal diffusion coefficient across the two flames. Significant differences can be observed for the quantities in the low temperature regions. The heat capacity in the transcritical flame $(p=53$ bar) presents a strong peak in the density jump region $\left(Z \approx 3 \times 10^{-4}\right)$, whereas the $C p$ profile of the lower pressure flame $(p=47$ bar) does not experience such phenomenon. The same observations can be made on the evolution of the thermal diffusion coefficients across the flames, as presented in Fig. 12b. This thermal barrier is responsible for the difference measured in the temperature profiles in Fig. 11b. The high $C p$ region prevents the jet core temperature from increasing and the density gradient is sustained longer. This directly affects the destabilization processes [49]. From a modeling perspective, this aspect must be recovered, consequently, for high pressure combustion, the chemistry library must be constructed at the conditions of interest with a solver that uses detailed real-fluid thermodynamic and transport schemes.

\subsection{Mixing path and thermodynamic regimes}

A critical and recurrent question in the rocket community is the following: Can the presence of water in the burnt gases modify the critical properties of the mixture such that two-phase flow would appear? The detailed results obtained in the present study are used to answer this question.

For a single species flow, the thermodynamic regime of the fluid can be easily determined using the critical pressure $P^{c}$ and the crit- 


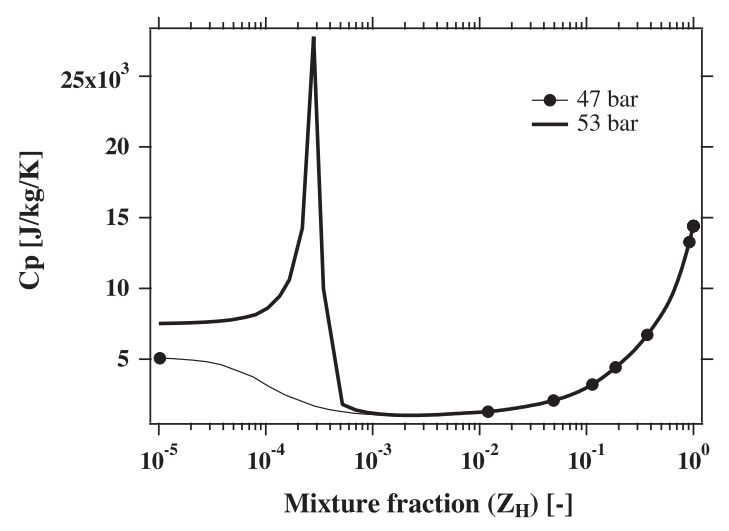

(a)

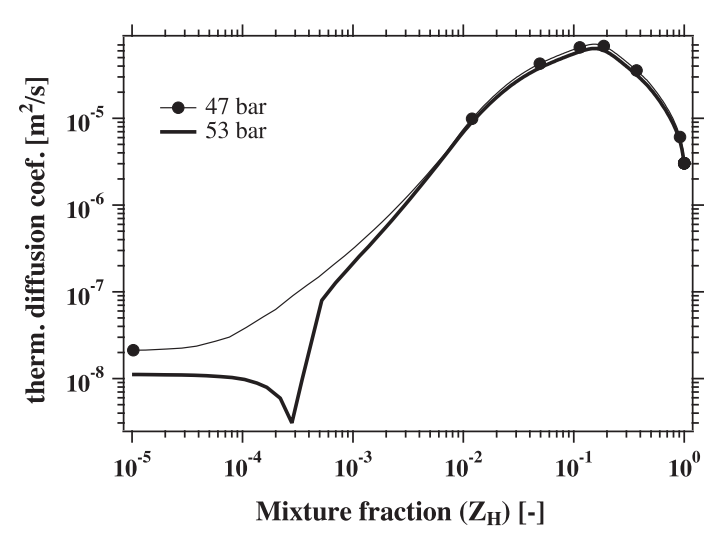

(b)

Fig. 12. Real fluid effects on thermodynamic and transport properties: (a) Heat capacity of the mixture $(C p)$ and (b) thermal diffusion coefficient $\left(D_{t h}\right)$ in mixturefraction space $\left(T_{\mathrm{O}_{2}}=154 \mathrm{~K}, T_{\mathrm{H}_{2}}=295 \mathrm{~K}\right.$ and $\left.a=10^{5} \mathrm{~s}^{-1}\right)$.

ical temperature $T^{c}$ of the species of interest. In the case of a binary system, or in the presence of a flame generating combustion products, the thermodynamic regime is much more complex to evaluate. Equilibrium calculations and experiments show that mixing can induce significant variations in critical properties [50]. As a result, the mixing path could cross the saturation line, leading to a classical two-phase flow regime. In this situation, single-phase methods are no longer valid and other numerical approaches must be considered to handle the discontinuity between phases.

Here we study the different thermodynamic regimes encountered by the mixture. The critical temperature of the mixture $T_{\text {mix }}^{c}$ is evaluated with Li's rule [51]:

$\phi_{j}=\frac{X_{j} V_{j}^{c}}{\sum_{i} X_{i} V_{i}^{c}}$
$T_{\text {mix }}^{c}=\sum_{j} \phi_{j} T_{j}^{c}$

where $V_{i}^{c}$ and $T_{j}^{c}$ are the critical volume and temperature of the $j$ th species respectively. These values are extracted from the NIST data base [8].

The critical pressure of the mixture $\left(P_{\text {mix }}^{c}\right)$ is given by the modified Prausnitz and Gunn approach [52]:

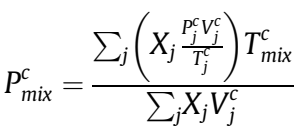

where $P_{j}^{c}$ is the critical pressure of the $j$ th species [8].

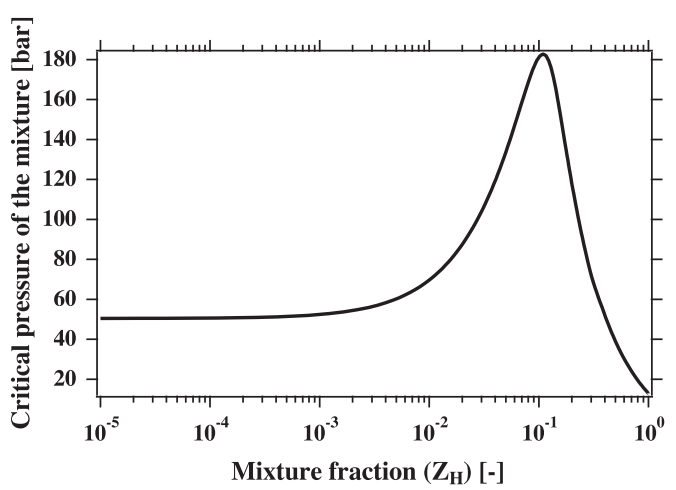

Fig. 13. Critical pressure of the mixture $P_{\text {mix }}^{c}$ (Eq. (21)) across the flame in mixture fraction space $\left(T_{O_{2}}=120 \mathrm{~K}, T_{\mathrm{H}_{2}}=295 \mathrm{~K}, P=70\right.$ bar and $\left.a=10^{5} \mathrm{~s}^{-1}\right)$.

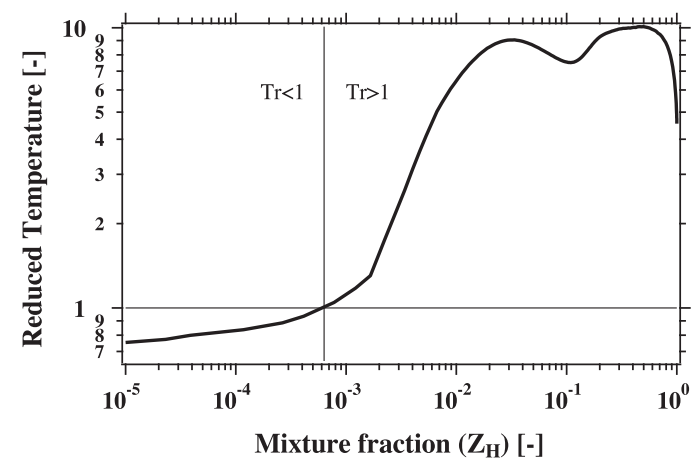

(a)

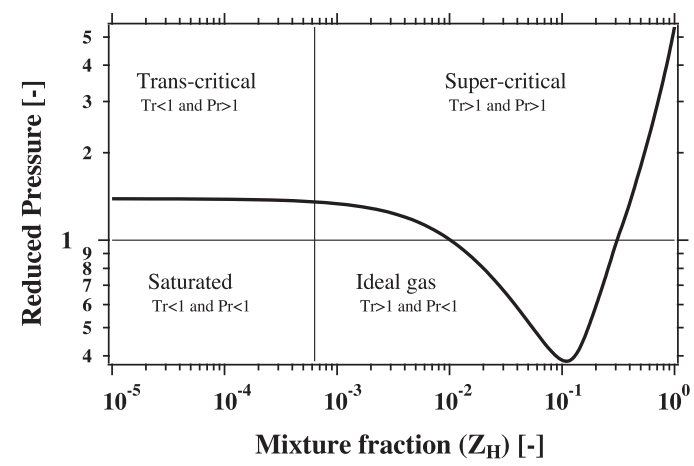

(b)

Fig. 14. Reduced temperature $T^{r}$ (a) and reduced pressure $P^{r}(\mathrm{~b})$ across the flame in mixture fraction space $\left(T_{O_{2}}=120 \mathrm{~K}, T_{\mathrm{H}_{2}}=295 \mathrm{~K}, P=70\right.$ bar and $\left.a=10^{5} \mathrm{~s}^{-1}\right)$.

Using the results from previous sections, the thermodynamic regime across the flame can be studied in mixture fraction space. For the present analysis, a flame at 70 bar and at a strain rate of $a=10^{5} \mathrm{~s}^{-1}$ is employed. The critical pressure of the mixture along the mixing path between oxygen and hydrogen is shown in Fig. 13. One can observe that indeed in the flame region $\left(Z_{H} \approx 0.1\right)$, the critical pressure of the mixture can be several time larger than the critical pressure of oxygen. To investigate the thermodynamic regime along the mixing path, the reduced pressure $P^{r}=P / P_{\text {mix }}^{c}$ and reduced temperature $T^{r}=T / T_{\text {mix }}^{c}$ are define (where $T$ is the temperature across the flame). These two quantities are presented Fig. 14.

Figure 14a shows that on the oxygen side (small values of $Z_{H}$ ) the temperature of the flow is below the critical temperature. Then the oxygen is heated up by heat transfer and at $Z_{H} \approx 6 \times 10^{-4}$, the 
reduced temperature of the mixture becomes greater than unity. In the flame zone $\left(Z_{H} \approx 0.1\right)$ and in the hydrogen stream $\left(Z_{H} \approx 1\right)$, the reduced temperature of the mixture is much greater than unity. This allows to draw a regime diagram in mixture fraction space to distinguish two different thermodynamic regions. When $Z_{H}<6 \times 10^{-4} \Rightarrow T^{r}<1$, two-phase flow effects may occur if the reduced pressure is low enough. When $Z_{H}>6 \times 10^{-4} \Rightarrow T^{r}>1$, the mixture is not saturated and behaves like a dense gas.

In Fig. 14b, one can identify all of the thermodynamic regimes encountered across the flame:

- Liquid and gas can coexist when $P^{r}<1$ and $Z_{H}<6 \times 10^{-4}$ (this region is called "Saturated" in Fig. $14 \mathrm{~b}$ and a phase discontinuity may appear in this zone,

- The trans-critical regime is defined when $P^{r}>1$ and $Z_{H}<6 \times 10^{-4}$,

- The super-critical regime occurs when $P^{r}>1$ and $Z_{H}>6 \times 10^{-4}$,

- The Ideal-gas regime is defined when $P^{r}<1$ and $Z_{H}>6 \times 10^{-4}$.

Figure 14b shows that the mixing line never penetrates the saturated region, thus two-phase flow effects can never occur near $\mathrm{H}_{2}-\mathrm{O}_{2}$ flames if the operating pressure is higher than the critical pressure of oxygen. Four different regions can be identified along the mixing and burning path across the flame. For $Z_{H}>6 \times 10^{-4}$, the mixture is mostly composed of dense oxygen in a transcritical compressed-liquid state. Due to the presence of the flame, the mixture is heated-up and reaches a super-critical state for $6 \times 10^{-4}<Z_{H}<10^{-2}$. In this region, the mixture is still mostly composed of oxygen, and behaves as a dense gas. Molecular diffusion processes become more efficient. In the range: $10^{-2}<Z_{H}<0.3$, the concentration of water is the most important in the mixture. This is where the highest temperatures are reached and the mixture behaves like an ideal gas. For mixture fractions $Z_{H}>0.3$, the mixture is in a super-critical state. In this zone, hot products mix with gaseous hydrogen and the mixture has the properties of a gas.

\subsection{Summary of detailed flame structure analysis}

Effects of strain rate, pressure, temperature and real-fluid phenomena on hydrogen-oxygen flame at supercritical pressures have been investigated in a modeling context. The main results are summarized in Table 4

\section{Consequences on the flamelet approach:}

- The first result of this study is that, for the conditions of interest, the flame is robust to strain and subsequently, the scalar dissipation rate does not have to be taken into account as a tabulation parameter.

- Pressure has a limited impact on flame structure (in mixture fraction space) at supercritical pressure and can also be neglected as a table input parameter.

- In the flame zone, temperature profile is insensitive to reactant temperatures, then temperature can be omitted as a dimension of the look-up table. In cold regions, however, stream temperatures can change due to long residence times (far downstream of the injector) and conduction effects. To capture these processes, an equation for energy must be included in the governing system of the flamelet approach.

- At supercritical pressures, non-idealities induced strong variations in thermodynamic and transport properties. These variations have a direct impact on the temperature profiles and have to be taken into account in the tabulation. The consequence is that look-up tables have to be generated by dedicated solvers at the conditions of interest.

- The final significant result is that along the mixing path, the mixture thermodynamic state never reaches a saturated state where two-phase flow may occur. This point demonstrates that the present dense-fluid approach coupled with an appropriate equation of state and realistic transport and thermodynamics is adapted to construct the table of the flamelet model.

\section{Model description and tabulation}

The ultimate goal of this study is to develop a combustion model that reproduces the flame behavior in a rocket engine, where temperature fluctuations, pressure waves and turbulent strain variations are present. This implies that the energy (or enthalpy) transport equation must be conserved in the system and that the flame must be represented as a source term. For this situation, the system of equations reduces to:

- Mass (Eq. (1)).

- Momentum (Eq. (2)).

- Mixture fraction:

Table 4

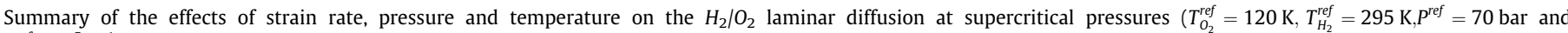
$a^{r e f}=10^{5} \mathrm{~s}^{-1}$ ).

\begin{tabular}{|c|c|c|}
\hline & Physical space & Mixture fraction space \\
\hline \multirow[t]{2}{*}{ Effect of strain } & $\begin{array}{l}\text { - The flame is very robust, } T_{\max } \approx \text { constant for } \\
a<5 \times 10^{6} \mathrm{~s}^{-1}\end{array}$ & - Temperature and species distributions are insensitive to strain for $a<5 \times 10^{6} \mathrm{~s}^{-1}$ \\
\hline & - $\delta_{f l m} \propto 1 / \sqrt{a}$ and $\dot{Q}_{s} \propto \sqrt{a}$ & - $\dot{\omega}_{T}$ increases when $a$ increases \\
\hline \multirow[t]{2}{*}{ Effect of pressure } & - $T_{\max } \approx T_{\max }\left(P^{r e f}\right) \pm 3 \%$ for $53 \mathrm{bar}<P<90$ bar & $\begin{array}{l}\text { - For } 53 \text { bar }<P<90 \text { bar temperature and species distributions are almost insensitive } \\
\text { to pressure variations }\end{array}$ \\
\hline & - $\delta_{f l m} \propto 1 / \sqrt{P}$ and $\dot{Q}_{s} \propto \sqrt{P}$ & $\begin{array}{l}\text { - Transport and thermodynamic parameters vary slightly with pressure } \\
\text { - } \dot{\omega}_{T} \text { increases when Pincreases. }\end{array}$ \\
\hline \multirow[t]{2}{*}{ Effect of temperature } & $\begin{array}{l}\text { - In the flame zone, temperature and species } \\
\text { profiles (not shown) are unchanged compared to } \\
\text { the reference flame }\end{array}$ & - Temperature and species distributions are unaffected in the flame region \\
\hline & $\begin{array}{l}\text { - Density and thermodynamic properties may } \\
\text { experience significant variations away from the } \\
\text { flame }\end{array}$ & $\begin{array}{l}\text { - Away from the flame, temperature variations are observed due to boundary } \\
\text { conditions } \\
\text { - Transport and thermodynamic properties are sensitive to oxygen inlet temperature } \\
\text { and can experience strong non-linear variations }\end{array}$ \\
\hline Real-fluid effects & $\begin{array}{l}\text { - In the flame, real-fluid processes do not impact } \\
\text { temperature } \\
\text { - Density may varies significantly }\end{array}$ & $\begin{array}{l}\text { - Due to real-fluid effects, large temperature differences ( } 16 \% \text { in the present case) can } \\
\text { be observed in the density jump region } \\
\text { - Non-idealities in thermodynamic and transport properties are responsible for this } \\
\text { temperature difference }\end{array}$ \\
\hline
\end{tabular}




$$
\frac{\partial}{\partial t}(\rho Z)+\nabla \cdot(\rho Z \mathbf{u})=\nabla \cdot \mathbf{q}_{Z}
$$

where

$$
\mathbf{q}_{Z}=\rho D_{Z} \nabla Z
$$

here $D_{Z}$ is chosen to have $L e_{Z}=1\left(L e_{Z}\right.$ is the Lewis number of $Z$ ), - Total non-chemical energy:

$$
\frac{\partial}{\partial t}(\rho E)+\nabla \cdot[(\rho E+P) \mathbf{u}]=\nabla \cdot\left[-\mathbf{q}_{E}^{\text {model }}+M^{2}(\tau \cdot \mathbf{u})\right]+\dot{Q}_{E}^{\text {model }},
$$

where the energy diffusion flux is modeled by the relation:

$$
\mathbf{q}_{E}^{\text {model }}=-\lambda \nabla T+\mathbf{q}_{z}\left(h_{s}^{H_{2}}-h_{s}^{O_{2}}\right),
$$

where $h_{s}^{H_{2}}$ and $h_{s}^{O_{2}}$ are the sensitive enthalpies of hydrogen and oxygen, respectively.

$\dot{Q}_{E}^{\text {model }}$ is the model source term representing the flame.

A direct tabulation of the energy source term is not an optimal approach for two reasons. First, heat release is a very non-linear term that would significantly increase interpolation errors. Second, heat release is sensitive to strain rate and pressure variations (contrary to the flame temperature), then a tabulation of this source term would require additional dimensions, degrading interpolation accuracy.

Another method is to rely on the fact that the flame temperature is almost insensitive to thermodynamic and flow conditions. It is then possible to define a source term that allow us to recover the correct temperature:

$$
\dot{Q}_{E}^{\text {model }} \approx \Gamma \frac{\left(\rho h_{t}\right)^{\text {flame }}-\rho h_{t}}{\Delta t},
$$

where $h_{t}^{\text {flame }}$ and $\rho^{\text {flame }}$ are the total sensitive enthalpy and the density in the flame respectively, $\Delta t$ is the time step in the computation and $\Gamma$ is test function that detects the flame zone.

In preliminary studies it was shown the reaction zone is not significantly affected by pressure and temperature variations contrary to non-reacting regions. To make the solver capable of reproducing compressibility and temperature effects, the model source term must modify the enthalpy in the flame zone only.

Consequently a flame detection function $\Gamma$ is employed, which is equal to unity in the flame front and zero otherwise. This function is defined as:

$\Gamma=\frac{1}{2}\left(1+\tanh \left(\frac{Z-Z_{\min }^{\text {flame }}}{\Delta_{Z}}\right)\right) \times \frac{1}{2}\left(1-\tanh \left(\frac{Z-Z_{\max }^{\text {flame }}}{\Delta_{Z}}\right)\right)$, where $Z_{\min }^{\text {flame }}$ and $Z_{\max }^{\text {flame }}$ are the flame boundaries in mixture fraction space, and $\Delta_{Z}$ controls the smoothness of the test function. From previous results, the flame is located in the range: $0.01<Z<0.99$ and an optimal value of $\Delta_{Z}=5 \times 10^{-3}$ is used. The model performances stay satisfactory as long as the lower cut-off value remains above $Z=10^{-3}$, below this value, the model interferes with transcritical effects (see Fig. 10 for example).

This approach is fairly classical, but encompasses key features required to capture strain, pressure and temperature variations effects. In the flame zone, flow characteristics are extracted from the look-up table and its coupling with the solver (see Section 4.1). In non-reacting regions, pressure, temperature and strain rate effects are taken into account through momentum, mixture fraction and the energy equation. In the following we consider different modeling strategies.

\subsection{Modeling strategies}

It was shown in Section 3 that transport properties and thermodynamic quantities depend on pressure and temperature conditions. Two main strategies can be followed to capture these dependencies. One is very general an can be applied to any solver. The second approach takes advantage of the capabilities of the present solver.

\section{- General formulation:}

For this approach, the input parameters of the table are $Z, P$ and the enthalpy of the mixture. The outputs are the mass and the mixture composition ( $\rho^{\text {table }}$ and $\left.Y_{i}^{\text {table }}\right)$, the transport properties $\left(\lambda^{\text {table }}, v^{\text {table }}, \operatorname{Pr}^{\text {table }}\right.$ ) (note that $S c_{Z}=\operatorname{Pr}$ if $L e_{Z}=1$ applies) and the thermodynamic parameters $\left(h_{t}^{\text {table }}, C_{p}^{\text {table }}, C_{v}^{\text {table }}, \gamma^{\text {table }}\right)$. The three input parameters are required to capture pressure and temperature effects on the flame structure and $N$ opposed-jet flames must be computed to cover the applicable $P-T$ space. Finally, the transport equations must be advanced in time. Note that strain rate effects are taken into account through the governing system. Scalar dissipation rate is not required as a table input parameter since it does not modify the thermo-chemical structure of the flame.

- Method adapted to the present solver:

This second approach takes advantage of the property evaluation scheme embedded in the solver (see Section 2.2). This scheme evaluates thermodynamic and transport properties from a given $\left(P, T, Y_{i}\right)$ set of conditions. Two distinct regions are considered in the flow. In the flame zone, the flamelet model is activated and the source term described in Eq. (26) is used to recover the temperature field. In the non-reacting region of the

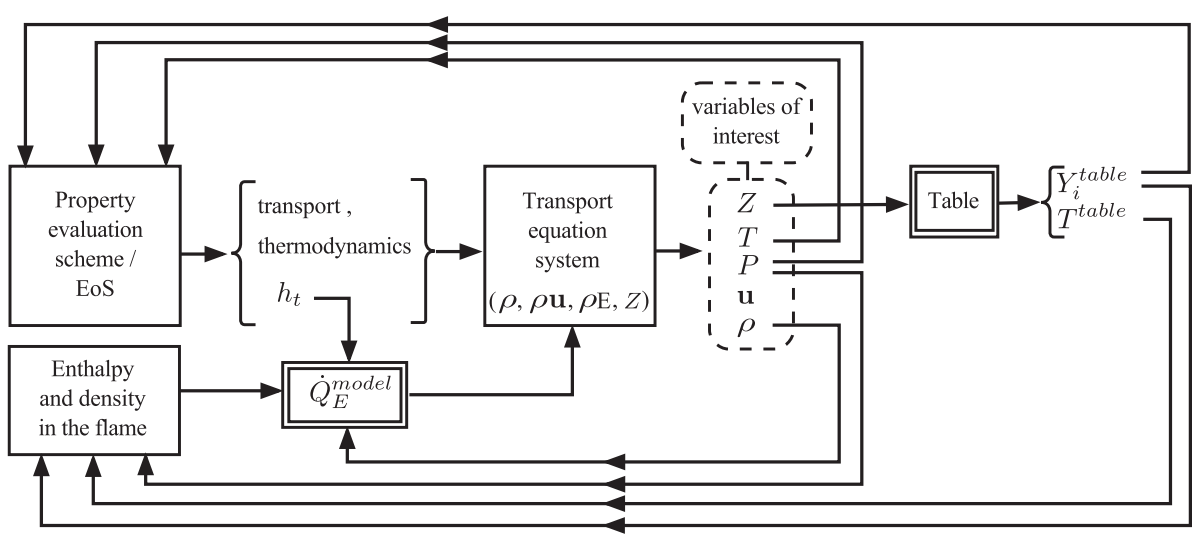

Fig. 15. Model diagram ( $\dot{Q}_{E}^{\text {model }}$ is defined in Eq. (26)). 
flow, a standard compressible governing system is employed to determine the temperature. Species mass fractions are interpolated from the look-up table in the entire flow field and pressure is recovered from the equation of state. Note that the term $\left(\rho h_{t}\right)^{\text {flame }}$ used in Eq. (26) is estimated from the temperature and species profiles in the flame $\left(Y_{i}^{\text {table }}\right.$ and $\left.T^{\text {table }}\right)$ and the local pressure $P$. The chemistry table is simplified to a one-dimensional manifold: $Z \rightarrow\left(Y_{i}^{\text {table }}, T^{\text {table }}\right)$, which can be easily constructed with a single opposed-jet flame calculation. This provides a significant simplification in the tabulation compared to the general approach. In Section 5, it will be demonstrated how this method based on a single flame calculation can recover pressure and strain rate effects.

A schematic of the coupling between the solver and the combustion model is represented in Fig. 15.

In the general formulation, the transport and thermodynamic properties are directly embedded in the chemical tabulation. By decoupling combustion from transport and thermodynamics, the present model is capable of accurately predicting pressure, strain, and heat transfer effects on the reacting flow. In addition, as only temperature and mass fractions are extracted from the table, the present method limits interpolation errors and at each location in the domain, transport and thermodynamic properties are in perfect agreement with flow conditions.

\subsection{Tabulation strategy}

When complex chemistry is used, especially with hydrogenoxygen combustion, differential diffusion effects are significant and the classical assumption of unity Lewis numbers is inconsistent. One of the main issues is the definition of the mixture fraction $Z$ which is a passive scalar. To circumvent this problem, Bilger defined a mixture fraction based on local element balancing [53]. Another method adopted by Pitsch and Peters is to directly define the passive variable by a conservation equation [54]. The latter has been used in the present study.

In the opposed jet calculations, nine species of the chemical mechanism are transported $\left(\mathrm{H}_{2}, \mathrm{O}_{2}, \mathrm{OH}, \mathrm{H}_{2} \mathrm{O}, \mathrm{H}, \mathrm{O}, \mathrm{HO}_{2}, \mathrm{H}_{2} \mathrm{O}_{2}, \mathrm{~N}_{2}\right)$ and an additional transport equation is added for the passive scalar $Z$. Decoupling between species and $Z$ ensures correct mapping of the flame structure in $Z$-space. The Schmidt number of $Z\left(S c_{Z}\right)$ can be arbitrary. In the present work a unity Lewis number for the mixture fraction is assumed $L e_{Z}=1 \Rightarrow S c_{Z}=P r$, as recommended in [54]. The generation of the table was carried out with a single counterflow flame in the two-dimensional configuration used in the previous sections. The strain rate was fixed to $a=10^{5} \mathrm{~s}^{-1}$ and the thermodynamic conditions were: $T_{\mathrm{O}_{2}}=120 \mathrm{~K}, T_{\mathrm{H}_{2}}=295 \mathrm{~K}$ and $P=70 \mathrm{bar}$.

\section{Model performance}

The model was compared to detailed calculations to assess its performance and sensitivity to strain, pressure, and inlet temperature. Figure 16 presents a comparison in terms of density, temperature and species. The first observation is that the model facilitates recovery of the temperature profile in mixture fraction space. Recall that the temperature is not directly extracted from the lookup table, but instead from the source term based on enthalpy in the energy equation.

A second observation is that the temperature profile in physical space is in good agreement with the detailed computation. The flame structure obtained with the model is slightly thinner than the reference flame, but the temperature in the density jump region is recovered correctly. This implies that the density gradient is also correct, as well as the magnitude of the oxygen density in the cold region. The model must preserve the density values in

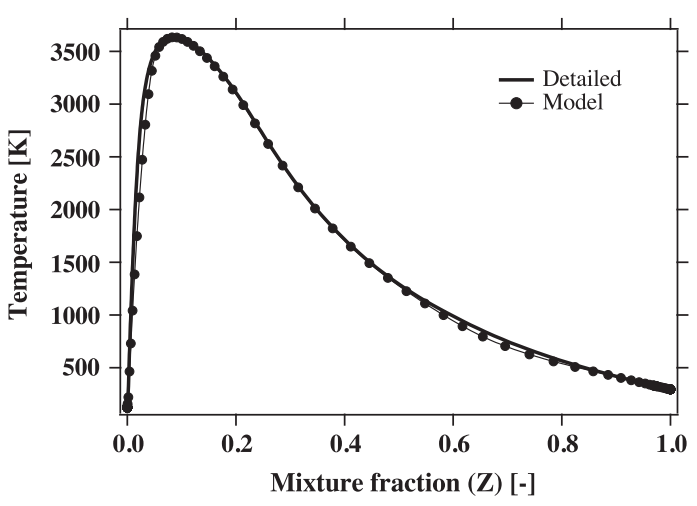

(a)

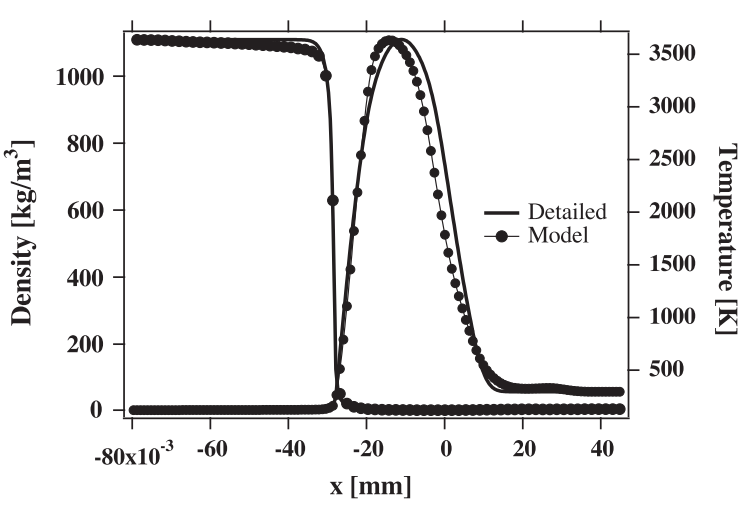

(b)

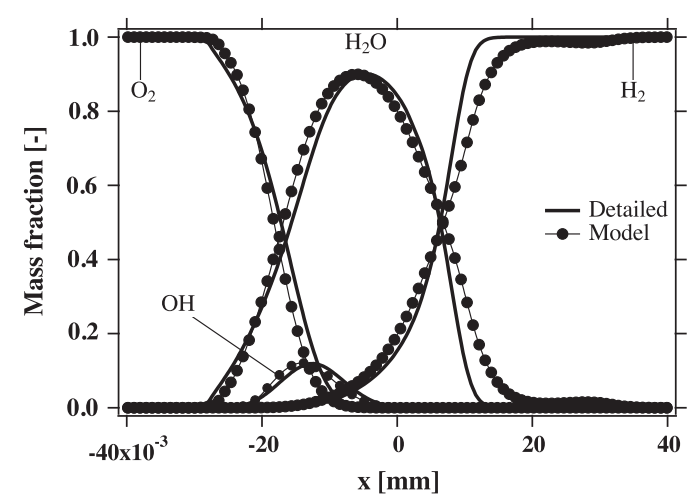

(c)

Fig. 16. Comparison between the tabulated-chemistry model and the detailed computation. (a) Temperature profile in Z-space, (b) temperature and density distributions in physical space and (c) mass fraction profiles of major species in physical space $\left(T_{O_{2}}=120 \mathrm{~K}, T_{\mathrm{H}_{2}}=295 \mathrm{~K}, P=70\right.$ bar and $\left.a=10^{5} \mathrm{~s}^{-1}\right)$.

the non-reacting zones of the flow and in the density gradient close to the flame to accurately capture mixing processes and liquidoxygen jet interactions with the flow dynamics [49]. Figure 16c shows the corresponding species profiles extracted from the table. Good agreement is observed between the model and the reference calculation, with only minor differences on the hydrogen side.

Figure 17 presents the sensitivity of the model to strain rate, pressure and inlet temperature variations. The previous investigation showed that the strain rate modifies the thickness of the reaction zone due to dynamic effects. Figure 17a confirms that the model reproduces the same trend, giving the correct thickness of the flame region. 


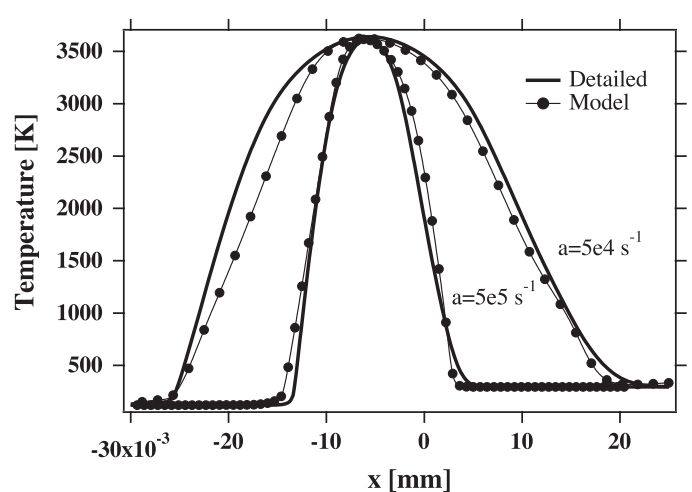

(a)

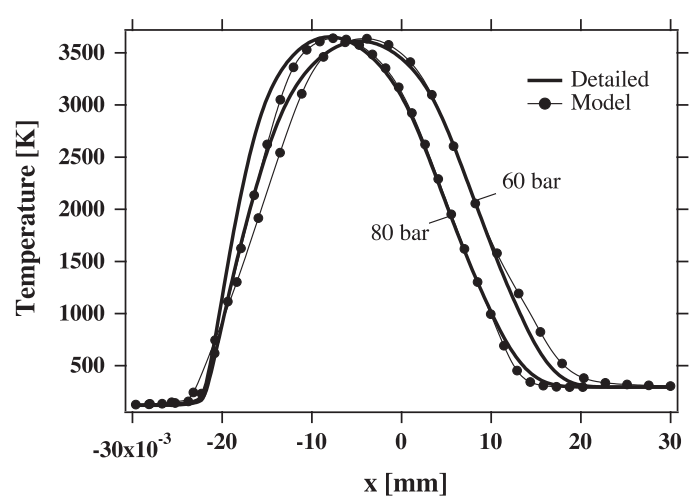

(b)

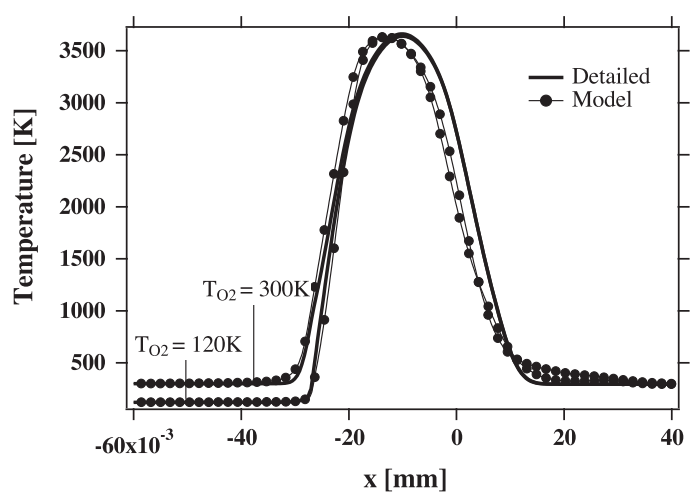

(c)

Fig. 17. Comparison between the model and the detailed computations: (a) sensitivity of the model to strain rate $\left(T_{O_{2}}=120 \mathrm{~K}, T_{\mathrm{H}_{2}}=295 \mathrm{~K}\right.$ and $\left.P=70 \mathrm{bar}\right)$, (b) sensitivity of the model to pressure $\left(T_{\mathrm{O}_{2}}=120 \mathrm{~K}, T_{\mathrm{H}_{2}}=295 \mathrm{~K}\right.$ and $\left.a=10^{5} \mathrm{~s}^{-1}\right)$ and (c) sensitivity of the model to inlet temperature $\left(T_{\mathrm{H}_{2}}=295 \mathrm{~K}, P=70 \mathrm{bar}\right.$ and $\left.a=10^{5} \mathrm{~s}^{-1}\right)$.

The fact that the flame sensitivity to strain rate variations is correctly captured, indicates that the model is able to predict the heat release rate dependency on strain. Indeed, it was shown in Sections 3.3 and 3.4 that for hydrogen-oxygen combustion, the fast chemistry assumption applies. In this case, heat release compensates exactly for heat losses due to diffusion processes [28]:

$\dot{\omega}_{T}=-\frac{1}{2} \rho \chi \frac{\partial^{2} T}{\partial Z^{2}}$

In this equation, the term $\rho \chi$ comes from mixing processes and is obtained using the governing equations. The other term: $\partial^{2} T / \partial Z^{2}$ represents the chemical effects and is extracted from the tabulation

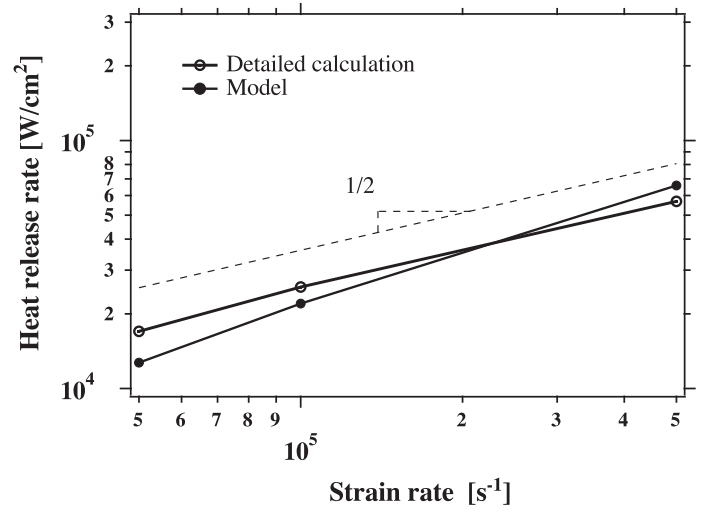

Fig. 18. Strain effect on heat release rate $\left(\dot{Q}_{s}\right.$, defined in Eq. (16)): comparison between the present model and detailed computations of Section 3.3 $\left(T_{O_{2}}=120 \mathrm{~K}, T_{H_{2}}=295 \mathrm{~K}\right.$ and $P=70$ bar $)$.

of the model. This term was shown to be invariant with respect to strain and pressure. Consequently, the model naturally recovers the impact of strain and pressure (through the term $\rho \chi$ ) even though a one dimensional manifold $\left(Z \rightarrow\left(Y_{i}^{\text {table }}, T^{\text {table }}\right)\right)$ is employed. Figure 18 shows the heat release versus strain rate and one can observe that the model is in good agreement with detailed simulations. The ability of the model to capture this effect is crucial since the coupling between local strain rate and heat release plays an important role in combustion stability processes.

The sensitivity of the model to pressure variations is also correctly recovered as shown in Fig. $17 \mathrm{~b}$. The impact of pressure on the flame thickness is captured with a satisfactory accuracy. This aspect is also a requirement for the study of flame stability in high pressure combustors. Pressure and strain rate fluctuations both result in local variations of heat release that can excite the acoustic modes of the burner and lead to combustion instabilities.

Figure $17 \mathrm{c}$ shows the sensitivity of the model to inlet temperature changes. For both oxygen inlet temperatures shown in the figure and the temperature across the flame front is correctly captured by the model. For $T_{\mathrm{O}_{2}}=300 \mathrm{~K}$, the injection temperature is supercritical and thermodynamic and transport coefficients are significantly different from transcritical conditions $\left(T_{\mathrm{O}_{2}}=120 \mathrm{~K}\right)$. Results in Fig. 17c demonstrate that the model can capture these changes and can be used to investigate the effect of heat exchanges on flame stability.

\section{Conclusion}

The main objective of the present work was to develop a robust high-pressure combustion model based on a detailed analysis of the hydrogen-oxygen flame at near-critical and supercritical conditions. The main goal is to treat flame stability in cryogenic rocket engines at high Reynolds number conditions. Flame stability in high pressure devices is affected by pressure and local strain variations as well as temperature fluctuations.

A literature review of previous investigations suggests that a flamelet approach based on tabulated chemistry is appropriate. Thus, to define the relevant model parameters, the first step was to study the flame structure and its sensitivity to strain, pressure, and temperature under realistic flow conditions. An canonical opposed-jet configuration was designed to perform the study.

Analysis revealed that the flame is thin and very robust over a large range of strain rates. This validates the flamelet assumption, and allows one to simplify the modeling approach since scalar dissipation rate can be ignored in the model tabulation. In addition, it was shown that pressure has a limited impact on flame structure in 
mixture fraction space at supercritical pressures. Thus, it can be omitted as a table input parameter. However, pressure and strain rate fluctuations induce variations in heat release. To take these effects into account, the governing system must include a transport equation for energy. Strain effects are naturally reproduced by solving mass, momentum, and mixture fractions transport equations. It was shown that in the reaction zone, the flame structure is almost insensitive to temperature variations contrary to nonreacting regions and close to the density gradient. In the density jump region, small variations in the inlet temperature may lead to strong changes in thermodynamic variables due to non-ideal behavior. Again, a transport equation for energy is required to capture temperature effects in non-reacting zones. In the flame, enthalpy is modified by the combustion model to recover the correct temperature.

A key new result obtained in this study is the impact of nonideal high pressure effects on the flame structure. At supercritical pressure, non-idealities induced strong variations in thermodynamic and transport properties. These variations have a direct impact on the temperature profiles and have to be taken into account in the tabulation. The consequence is that look-up tables have to be generated by dedicated solvers at the conditions of interest. The detailed computations also revealed that along the mixing path, the presence of water from combustion products does not lead to a saturated mixture where two-phase flow may be observed. This result is significant since it proves that a single-fluid approach is relevant to simulate supercritical flows.

Based on these conclusions, a flamelet-like approach has been defined that takes into account compressibility, strain, and temperature effects.

The flamelet approach is coupled with a compressible governing system to handle high-pressure effects. In the flame region, the enthalpy is modified by a compressible source term (Eq. (26)) to recover the correct temperature field. This source term is evaluated from the local pressure and enthalpy (from the governing system and the equation of state) and from the table outputs $T^{\text {table }}$ and $Y_{i}^{\text {table }}$ (that are insensitive to strain and pressure effects in the present case). To clearly explain why this model is able to capture pressure and strain rate effects although it is based on an onedimensional tabulation $\left(Z \rightarrow T^{\text {table }}, Y_{i}^{\text {table }}\right)$, one can recast the model source term as: $\dot{\omega}_{T}=-1 / 2 \rho \chi \partial^{2} T / \partial Z^{2}$. The term $\partial^{2} T / \partial Z^{2}$ represents chemical effects and for the present conditions in insensitive to strain and pressure and can be model with a one-dimensional flamelet manifold. The second term $\rho \chi$ represents mixing effects which are evaluated through the governing system. It is this latter term that embeds pressure and strain rate effects.

The model was implemented in the LES solver and its accuracy was tested in a laminar opposed-jet configuration. Model sensitivity to strain rate, pressure and temperature was tested and good agreements were obtained in comparison with detailed computations. In particular, the impacts of strain and pressure on local heat release rate were correctly recovered. This capability of the model is a requirement to study combustion stability in rocket engines.

Another substantial result is that the model preserves correct values of density values in the liquid oxygen region as well as the density gradient in the vicinity of the flame. This aspect is of significant importance for the simulation of combustion in practical devices, where the destabilization and mixing of the dense-fluid jet are strongly affected by both density magnitude and its gradient.

In future work we will define an appropriate turbulence closure and perform LES computations in practical configurations. Several closures will be studied such as presumed-pdf approaches. Different ways to obtained the variance of the mixture fraction will be investigated, from a direct analytical method to a full transport equation approach.

\section{Acknowledgments}

The US Department of Energy, Office of Basic Energy Sciences, Division of Chemical Sciences, Geosciences, and Biosciences supported this work. Sandia National Laboratories is a multiprogram laboratory operated by Sandia Corporation, a Lockheed Martin Company, for the United States Department of Energy under Contract DE-AC04-94-AL85000.

\section{References}

[1] R.C. Reid, J.M. Prausnitz, B.E. Polling, The Properties of Liquids and Gases, fourth ed., McGraw Hill, New York, 1987

[2] C. Angelberger, F. Egolfopoulos, D. Veynante, Flow Turbul. Combust. 65 (2000) 205-222.

[3] M. Boileau, G. Staffelbach, B. Cuenot, T. Poinsot, C. Bérat, Combust. Flame 154 (2008) 291-321.

[4] F. Di Mare, W.P. Jones, K. Menzies, Combust. Flame 137 (2001) 278-295.

[5] P. Moin, S.V. Apte, Am. Inst. Aeronaut. Astronaut. J. 44 (2006) 698-708.

[6] J. Oefelein, Progr. Aerospace Sci. 42 (2006) 2-37.

[7] J.C. Oefelein, 41st Aerospace Sciences Meeting and Exhibit, 2003.

[8] P. Linstrom, W. Mallard, NIST Chemistry WebBook, NIST Standard Reference database, vol. 69, National Institute of Standards and Technology (NIST), Gaithersburg MD, 20899, 2005

[9] S. Candel, G. Herding, R. Snyder, P. Scouflaire, C. Rolon, L. Vingert, M. Habiballah, F. Grisch, M. Pealat, P. Bouchardy, D. Stepowski, A. Cessou, P. Colin, J. Propul. Power 14 (1998) 826-834.

[10] S. Candel, M. Juniper, G. Singla, P. Scouflaire, C. Rolon, Combust. Sci. Technol. 178 (2006) 161-192.

[11] B. Ivancic, W. Mayer, G. Krülle, D. Brüggemann, AIAA Paper, 1999.

[12] M. Juniper, A. Tripathi, P. Scouflaire, C. Rolon, S. Candel, The Structure of Cryogenic Flames at Subcritical and Supercritical Pressures, Centre National D’Etude Spatial, 2001.

[13] W. Mayer, B. Ivancic, A. Schik, U. Hornung, J. Propul. Power 17 (2001) 794-799.

[14] W. Mayer, H. Tamura, J. Propul. Power 12 (1996) 1137-1147.

[15] W. Mayer, H. Tamura, J. Propul. Power 16 (2000) 823-828.

[16] G. Singla, P. Scouflaire, C. Rolon, S. Candel, Combust. Flame 144 (2006) 151169.

[17] G. Ribert, N. Zong, V. Yang, L. Pons, N. Darabiha, S. Candel, Combust. Flame 154 (2008) 319-330.

[18] M. Juniper, N. Darabiha, S. Candel, Combust. Flame 135 (2003) 87-96.

[19] B. Ivancic, W. Mayer, J. Propul. Power 18 (2002) 247-253.

[20] N. Zong, G. Ribert, V. Yang, AIAA Paper, 2008.

[21] T. Schmitt, Y. Méry, M. Boileau, S. Candel, Proceedings of the Combustion Institute, 2010.

[22] S. Matsuyama, J. Shinjo, Y. Mizobuchi, S. Ogawa, AIAA Paper, 2006.

[23] S. Matsuyama, J. Shinjo, S. Ogawa, Y. Mizobuchi, AIAA Paper, 2010.

[24] L. Cutrone, P. De Palma, G. Pascazio, M. Napolitano, AIAA Paper, 2008.

[25] F. Demoulin, S. Zurbach, A. Mura, J. Propul. Power 25 (2009).

[26] J.C. Oefelein, Proc. Combust. Inst. 30 (2005) 2929-2937.

[27] J.C. Oefelein, Combust. Sci. Technol. 178 (2006) 229-252.

[28] T. Poinsot, D. Veynante, Theoretical and numerical combustion, in: R.T. Edwards, (Ed.), second ed., 2005.

[29] D.Y. Peng, D.B. Robinson, Ind. Eng. Chem. Fundam. 15 (1976) 59-64.

[30] J.C. Oefelein, General Package for Evaluation of Multicomponent Real-Gas and Liquid Mixture States at all Pressures, Sandia National Laboratories, Livermore, CA, 2009.

[31] S. Gordon, B.J. McBride, Computer Program for Calculation of Complex Chemical Equilibrium Compositions, Rocket Performance, Incident and Reflected Shocks, and Chapman-Jouguet Detonations, Technical Report SP273, NASA, 1971.

[32] R.J. Kee, F.M. Rupley, J.A. Miller, CHEMKIN-II: A Fortran Chemical Kinetics Package for the Analysis of Gas-Phase Chemical Kinetics, Technical Report Sandia National Laboratories, 1991.

[33] J. Ely, H.J.M. Hanley, Ind. Eng. Chem. Fundam. 20 (1981) 323-332.

[34] J. Ely, H.J.M. Hanley, Ind. Eng. Chem. Fundam. 22 (1983) 90-97.

[35] R. Bird, W. Stewart, E. Lighfoot, Transport Phenomena, John Wiley, New York, 1960.

[36] J. Hirschfelder, F. Curtiss, R. Bird, Molecular Theory of Gases and Liquids, John Wiley \& Sons, New York, 1964.

[37] S. Takahashi, J. Chem. Eng. Jpn. 7 (1974) 417-420.

[38] M. ÓConaire, H. Curran, J. Simmie, W. Pitz, C. Westbrook, Int. J. Chem. Kinet. 36 (2004) 603-622.

[39] M. Baum, T.J. Poinsot, D. Thévenin, J. Comput. Phys. 116 (1994) 247-261.

[40] T. Poinsot, S. Lele, J. Comput. Phys. 101 (1992) 104-129.

[41] D. Harrje, F. Reardon, Liquid Propellant Rocket Instability, Technical Report SP194, NASA, 1972.

[42] V. Yang, W. Anderson, Liquid Rocket Engine Combustion Instability, AIAA, 1995.

[43] N. Darabiha, V. Giovangigli, S. Candel, M. Smooke, Combust. Sci. Technol. 60 (1988) 267-285.

[44] J. Li, Z. Zhao, A. Kazakov, F. Dryer, Int. J. Chem. Kinet. 36 (2004) 566-575.

[45] T. Chung, M. Ajlan, L. Lee, K. Starling, Ind. Eng. Chem. Res. 27 (1988) 671-679 
[46] B. Chehroudi, J. Propul. Power 26 (2010) 1153-1160.

[47] B. Knapp, Z. Farago, M. Oschwald, Interaction of LOX/GH2-Spray Combustion with Acoustics, in: 45th AIAA, Reno, NV, 2007, pp. 1-9.

[48] G. Searby, A. Nicole, M. Habiballah, E. Laroche, J. Propul. Power 24 (2008) 516523.

[49] I. Hannoun, H. Fernando, E. List, J. Fluid Mech. 189 (1988) 189-209.
[50] W. Streett, J. Calado, J. Chem. Thermodyn. 10 (1978) 1089-1100.

[51] C. Li, Can. J. Chem. Eng. 49 (1971) 709-710.

[52] J. Prausnitz, R. Gunn, AIChE J. 4 (1958) 430-435.

[53] R. Bilger, Symp. (Int.) Combust. 22 (1989) 475-488.

[54] H. Pitsch, N. Peters, Combust. Flame 114 (1998) 26-40. 